\title{
The Steroid Hormone 20-Hydroxyecdysone Enhances Neurite Growth of Drosophila Mushroom Body Neurons Isolated during Metamorphosis
}

\author{
Robert Kraft, Richard B. Levine, and Linda L. Restifo \\ Arizona Research Laboratories, Division of Neurobiology, University of Arizona, Tucson, Arizona 85721-0077
}

Mushroom bodies (MBs) are symmetrically paired neuropils in the insect brain that are of critical importance for associative olfactory learning and memory. In Drosophila melanogaster, the MB intrinsic neurons (Kenyon cells) undergo extensive reorganization at the onset of metamorphosis. A phase of rapid axonal degeneration without cell death is followed by axonal regeneration. This re-elaboration occurs as levels of the steroid hormone 20-hydroxyecdysone (20E) are rising during the pupal stage. Based on the known role of $20 \mathrm{E}$ in directing many features of CNS remodeling during insect metamorphosis, we hypothesized that the outgrowth of $\mathrm{MB}$ axonal processes is promoted by $20 \mathrm{E}$. Using a GAL4 enhancer trap line (201Y) that drives MB-restricted reporter gene expression, we identified Kenyon cells in primary cultures dissociated from early pupal CNS. Paired cultures derived from single brains isolated before the $20 \mathrm{E}$ pupal peak were incubated in medium with or without 20E for 2-4 d. Morphometric analysis demonstrated that MB neurons exposed to $20 \mathrm{E}$ had significantly greater total neurite length and branch number compared with that of MB neurons grown without hormone. The relationship between branch number and total neurite length remained constant regardless of hormone treatment in vitro, suggesting that $20 \mathrm{E}$ enhances the rate of outgrowth from pupal MB neurons in a proportionate manner and does not selectively increase neuritic branching. These results implicate $20 \mathrm{E}$ in enhancing axonal outgrowth of Kenyon cells to support MB remodeling during metamorphosis.

Key words: steroid hormone; ecdysteroids; metamorphosis; Drosophila melanogaster; polarity; mushroom body; Kenyon cells; neuronal remodeling; neurite outgrowth; cell culture
Steroid hormones play critical roles in orchestrating functional and structural changes of neurons and neuronal circuits throughout development in both vertebrates and invertebrates (for review, see Arnold and Gorski, 1984; Levine et al., 1995). Steroids regulate dendritic and axonal morphology (Kurz et al., 1986; Levine, 1989; VanderHorst and Holstege, 1997), dendritic regression and regrowth (Weeks, 1987; Truman and Reiss, 1988; Schubiger et al., 1998), synaptic density (Gould et al., 1990; Woolley and McEwen, 1992), and cell death (Truman and Schwartz, 1984; Robinow et al., 1993). Many of these hormonal effects have been reproduced on dissociated neurons in vitro (e.g., Levine and Weeks, 1996; Murphy and Segal, 1996). Furthermore, responses to hormone depend on the type and developmental stage of the cells before isolation (Prugh et al., 1992; Streichert et al., 1997).

During insect metamorphosis, the nervous system undergoes extensive reorganization, many features of which are controlled by the ecdysteroid molting hormone 20-hydroxyecdysone (20E) (Levine et al., 1991; Truman, 1996). In the fruit fly Drosophila

Received April 1, 1998; revised Aug. 13, 1998; accepted Aug. 17, 1998.

R.K. was supported in part by National Institutes of Health Research Training Grant NS07363. This work was funded by grants to L.L.R. from the John Merck Fund (Program in Developmental Disabilities in Children), the University of Arizona Small Grant Program, and National Institutes of Health (NS28495). We are indebted to M. Anezaki for invaluable assistance in photographic processing and morphometric analysis. The help of K. Della Croce, H. Foster, C. Hedgcock, P. Jansma, R. Luedeman, C. McGonigle, and C. Turner is also appreciated. We thank I. Vilinsky and N. Strausfeld for Drosophila stocks, P. Hurban for antibodies, and M. Vaskova for advice on immunostaining. R. Graf, L. Tolbert, and A. Yool provided thoughtful comments on this manuscript.

Correspondence should be addressed to Dr. Linda L. Restifo, Arizona Research Laboratories, Division of Neurobiology, University of Arizona, P.O. Box 210077 , Tucson, AZ 85721-0077.

Copyright (C) 1998 Society for Neuroscience $\quad 0270-6474 / 98 / 188886-14 \$ 05.00 / 0$ melanogaster, receptors for this steroid hormone are present in multiple isoforms with complex, dynamic expression patterns in the developing CNS (Truman et al., 1994). 20E activates a genetic regulatory hierarchy, mediated by several hormone-inducible transcription factors (Thummel, 1996), at least one of which is required for metamorphic reorganization of the CNS (Restifo and White, 1991). Downstream targets of some of these transcription factors are known for non-neural tissues (Bayer et al., 1996), and those that shape the responses of the nervous system to $20 \mathrm{E}$ are presently being identified (Liu and Restifo, 1998).

We have combined the primary cell culture approach with molecular genetic strategies available in Drosophila to study hormone action underlying nervous system reorganization during metamorphosis. Our initial focus has been on Kenyon cells, the intrinsic neurons of the mushroom bodies (MBs), because they represent the single largest neuronal population whose metamorphic transition in vivo has been described in Drosophila (Technau and Heisenberg, 1982). The MBs command considerable interest because they are essential for higher order sensory integration as well as learning and memory (de Belle, 1995; Davis and Han, 1996).

Unique anatomical features of the MBs have allowed direct examination of neuronal numbers and morphological integrity. Kenyon cell axons project together in a dense parallel array called the peduncle that splits into three lobes (Power, 1943; Yang et al., 1995). Overall MB morphology remains stable throughout metamorphosis. However, the number of axons, counted in crosssections through the peduncle, plummets dramatically at the onset of metamorphosis, without loss of cell bodies, and then increases as pupal development proceeds (Technau and Heisenberg, 1982). These ultrastructural data indicate that many Kenyon 
cell axons undergo retraction, followed by regeneration. Because the regrowth occurs as 20E levels are rising (Richards, 1981) and because the MBs express ecdysteroid receptors at this time (Truman et al., 1994), we hypothesized that 20E promotes the regeneration of pupal Kenyon cell axons. In this report, we demonstrate that pupal MB neurons can be identified in dissociated cell culture and that they respond to $20 \mathrm{E}$ when grown in vitro.

Parts of this paper have been published previously in abstract form (Kraft et al., 1997).

\section{MATERIALS AND METHODS}

Drosophila stocks. Flies were reared at $25^{\circ} \mathrm{C}$ on standard corn flouryeast-agar medium (Elgin and Miller, 1978). The P[GAL4] lines 30Y, 72Y, 201Y, c35, c739 (Yang et al., 1995), and c747 (Connolly et al., 1996) were tested for MB-specific GAL4 expression. The reporter line $\mathrm{UAS}_{\mathrm{G}^{-}}$ lac $Z$ (Brand and Perrimon, 1993) exhibits no detectable $\beta$-galactosidase ( $\beta$ gal) expression in the CNS (R. Kraft, unpublished observations). GAL4 activity was detected in the progeny of single-pair matings between homozygous $\mathrm{P}[\mathrm{GAL} 4]$ flies and homozygous $\mathrm{UAS}_{\mathrm{G}}$-lacZ flies using antibodies against $\beta$ gal, which is distributed throughout the cytoplasm.

Preparation of dissociated neuronal cell cultures. The techniques used to prepare and maintain cultures of dissociated Drosophila CNS tissue were adapted from those developed for Drosophila larval neurons (Wu et al., 1983) and Manduca pupal motor neurons (Prugh et al., 1992). Progeny from $201 \mathrm{Y} \times \mathrm{UAS}_{\mathrm{G}}$-lac $Z$ matings were collected as prepupae, sexed, and monitored in a humid $60 \mathrm{~mm}$ covered glass Petri dish to determine the time of head eversion, signifying the start of the pupal phase of metamorphosis (Bainbridge and Bownes, 1981). Five hours after head eversion, at a time estimated to be just before the onset of the pupal peak of 20E (Bainbridge and Bownes, 1988), the pupae were surface-sterilized for $1 \mathrm{~min}$ in $70 \%$ ethanol and rinsed three times in sterile deionized water. The CNS was removed from pupae using watchmaker forceps and immersed in culture medium without antibiotics (modified from O'Dowd, 1995): 1× Schneider's Insect Medium (Life Technologies, Gaithersburg, MD) with $10 \%$ fetal bovine serum (Hyclone, Logan, UT) and $50 \mu \mathrm{g} / \mathrm{ml}$ insulin (Sigma, St. Louis, MO). Brain tissue encompassing the MBs was regionally dissected away from the thoracoabdominal ganglion and optic lobes using minutien pins (Fine Science Tools, Foster City, CA). The isolated tissue was incubated for $1 \mathrm{hr}$ at room temperature in freshly prepared enzyme solution of $0.1 \mathrm{mg} / \mathrm{ml}$ collagenase (Worthington, Freehold, NJ) and $0.4 \mathrm{mg} / \mathrm{ml}$ dispase (Boehringer Mannheim, Indianapolis, IN) in Rinaldini's saline: $137 \mathrm{~mm} \mathrm{NaCl}, 2.68 \mathrm{~mm}$ $\mathrm{KCl}, 0.36 \mathrm{~mm} \mathrm{NaH}_{2} \mathrm{PO}_{4}, 11.9 \mathrm{~mm} \mathrm{NaHCO}$, and $5.55 \mathrm{~mm}$ glucose $(\mathrm{Wu}$ et al., 1983).

The tissue was washed by transferring it to $1 \mathrm{ml}$ of culture medium in a $1.5 \mathrm{ml}$ microf uge tube and centrif uging for $1 \mathrm{~min}$ at $1000 \mathrm{rpm}$. Medium $(900 \mu \mathrm{l})$ was removed and replaced with fresh culture medium, the tissue was again centrifuged for $1 \mathrm{~min}$ at $1000 \mathrm{rpm}$, and $800 \mu \mathrm{l}$ of medium was removed. To dissociate the cells, we triturated the tissue in the remaining $200 \mu \mathrm{l}$ of medium by flushing 40 times through a fire-polished, prewetted glass pipette and an additional 40 times through a prewetted $200 \mu \mathrm{l}$ sterile disposable micropipette tip. The suspension was dispensed in 100 $\mu \mathrm{l}$ aliquots into wells made by cutting an $8 \mathrm{~mm}$ hole in a plastic $35 \mathrm{~mm}$ culture dish (Corning, Corning, NY) and attaching a gridded glass coverslip (Bellco, Vineland, NJ) to the bottom with Sylgard (Dow Corning, Midland, MI). Before the addition of cells, the dish had been UV-sterilized, and the glass had been coated by exposure to a solution of $167 \mu \mathrm{g} / \mathrm{ml}$ Concanavalin A (Sigma) and $1.67 \mu \mathrm{g} / \mathrm{ml}$ mouse laminin (Collaborative Research, Bedford, MA) for $2 \mathrm{hr}$ at $37^{\circ} \mathrm{C}$.

For each hormone treatment experiment, six cultures were prepared from a single brain. Approximately $30 \mu \mathrm{l}$ of cell suspension was added to enough culture medium in each well to bring the volume to $100 \mu \mathrm{l}$. The cells were allowed to settle undisturbed for $2 \mathrm{hr}$ at $25^{\circ} \mathrm{C}$. Each dish was flooded with $900 \mu \mathrm{l}$ of culture medium and sealed with Parafilm (American National Can, Greenwich, CT). Cultures exposed to hormone received $900 \mu \mathrm{l}$ of medium containing $1 \mu \mathrm{g} / \mathrm{ml} 20 \mathrm{E}\left(2.1 \times 10^{-6} \mathrm{M}\right.$; Sigma). The concentration of a $20 \mathrm{E}$ stock solution prepared in deionized water was determined spectrophotometrically (Rees and Isaac, 1985). No $20 \mathrm{E}$ was detected by ELISA in the fetal bovine serum used in the culture medium (R. B. Levine, unpublished observations). To allow an objective analysis, the coding of paired cultures (one dish with and one dish without $20 \mathrm{E}$ ) was performed by a lab member who was not involved in the subsequent morphometric analyses that were done blind. The culture pairs were allowed to grow for $2 \mathrm{~d}$ (48 hr after plating), $3 \mathrm{~d}$ ( $72 \mathrm{hr}$ after plating), or $4 \mathrm{~d}\left(96 \mathrm{hr}\right.$ after plating) in a $25^{\circ} \mathrm{C}$ incubator.

Immunohistochemistry of whole-mount preparations and cell cultures. Larval and pupal CNS were dissected in cold PBS and fixed for 2-4 hr on ice in $4 \%$ formaldehyde (Ted Pella, Redding, CA) in $100 \mathrm{~mm}$ PIPES, pH 6.6, 1 mm EGTA, $2 \mathrm{~mm} \mathrm{MgSO}_{4}$, and 1\% Triton X-100 (modified from Sandstrom et al., 1997). After a $10 \mathrm{~min}$ wash in PBS, tissue was washed three times for $10 \mathrm{~min}$ each in blocking buffer (BB): $50 \mathrm{~mm}$ Tris- $\mathrm{HCl}, \mathrm{pH}$ $7.0,150 \mathrm{~mm} \mathrm{NaCl}, 0.25 \%$ Triton X-100, $0.25 \%$ casein (occasionally omitted), $0.02 \% \mathrm{Na}$ azide, $0.25 \%$ bovine serum albumin, and $2 \%$ normal goat serum. All washes were performed at room temperature. Tissue was incubated with primary antibodies in $\mathrm{BB}$ for $12-18 \mathrm{hr}$ at $4^{\circ} \mathrm{C}$ and then washed six times for $10 \mathrm{~min}$ each in $\mathrm{BB}$. Tissue was incubated with secondary antibodies in $\mathrm{BB}$ at room temperature in the dark for $3 \mathrm{hr}$ and then washed six times for 10 min each in BB in darkness. Tissue was briefly rinsed in $0.1 \mathrm{M}$ Tris- $\mathrm{HCl}, \mathrm{pH} 8.0$, and then mounted in $13.3 \%$ polyvinyl alcohol (PVA) with $1.7 \%$ DABCO (1,4-diazabicyclo[2,2,2]octane; Sigma) to minimize photobleaching (Banker and Goslin, 1991). Primary antibodies used were either a monoclonal mouse anti- $\beta$ gal (Promega, Madison, WI) at 1:2000 or a polyclonal rabbit anti- $\beta$ gal (Cappel, Durham, NC) at 1:5000, first preabsorbed for $16 \mathrm{hr}$ at $4^{\circ} \mathrm{C}$ by mixing with fixed third instar larval tissue. Secondary antisera used were either Cy3-conjugated goat anti-mouse at 1:500 or Cy3-conjugated goat anti-rabbit at 1:250 (Jackson ImmunoResearch, West Grove, PA). Confocal microscopy and image preparation were performed as described by Liu and Restifo (1998).

Immunohistochemical staining of cells in culture to identify $\beta$ galexpressing cells and to simultaneously visualize neuronal membranes used a method modified from that of Vallés and White (1986). This was achieved by double-labeling with anti- $\beta$ gal in combination with antihorseradish peroxidase (HRP) (Jan and Jan, 1982) that recognizes Drosophila neuron-specific glycoproteins (Wang et al., 1994; Sun and Salvaterra, 1995). The fixation, washes, and antibody incubations were performed with swirling on a platform rotator. Culture dishes were rinsed twice with $1 \mathrm{ml}$ of cold Ikeda Ringer's saline (130 mM NaCl, 4.7 $\mathrm{mm} \mathrm{KCl}, 1.8 \mathrm{~mm} \mathrm{MgCl}_{2}, 0.74 \mathrm{~mm} \mathrm{KH}_{2} \mathrm{PO}_{4}$, and $\left.0.35 \mathrm{~mm} \mathrm{Na}_{2} \mathrm{HPO}_{4}\right)$ and were fixed for $30 \mathrm{~min}$ at $4^{\circ} \mathrm{C}$ in $4 \%$ paraformaldehyde (J. T. Baker Chemical Company, Phillipsburg, NJ) in 0.1 m sodium phosphate buffer, $\mathrm{pH}$ 7.2. The dishes were washed three times for 20 min each in $1 \mathrm{ml}$ of PTN (0.1 M sodium phosphate buffer, $\mathrm{pH} 7.2,0.1 \%$ Triton X-100, and $0.1 \%$ sodium azide) and were then incubated with primary antibodies in PTN for $12-16 \mathrm{hr}$, all performed at $4^{\circ} \mathrm{C}$. The preabsorbed polyclonal rabbit anti- $\beta$ gal antiserum was used at 1:5000, and a polyclonal goat anti-HRP antiserum (Sigma) was used at 1:500. Alternatively, the monoclonal mouse anti- $\beta$ gal antibody was used alone at 1:4000. Dishes were rinsed with PTN and then washed five times for 20 min each in $1 \mathrm{ml}$ of PTN at room temperature. The dishes were incubated with secondary antibodies in PTN at $4^{\circ} \mathrm{C}$ in the dark for $3 \mathrm{hr}$, followed by a rinse and five 20 min washes in PTN at room temperature in the dark. A Cy2conjugated donkey anti-rabbit antiserum (Jackson ImmunoResearch) was used at 1:500, and a Lissamine Rhodamine (LRSC)-conjugated donkey anti-goat antiserum (Jackson ImmunoResearch) was used at $1: 250$. When the monoclonal mouse anti- $\beta$ gal antibody was used, Cy3conjugated donkey anti-mouse antiserum (Jackson ImmunoResearch) was used at 1:500 along with a fluorescein isothiocyanate-conjugated goat anti-HRP antiserum (Cappel) at 1:400. After a rinse with $0.1 \mathrm{M}$ Tris$\mathrm{HCl}, \mathrm{pH} 8.0,250 \mu \mathrm{l}$ of the PVA plus DABCO mountant was added, and the culture wells were covered with a glass coverslip.

To detect ecdysone receptors and $\beta$ gal in cultured neurons, a protocol modified from that of Robinow et al. (1993) was followed. Cultures were briefly rinsed in cold PBS $2 \mathrm{hr}$ after plating and then fixed for $20 \mathrm{~min}$ at $4^{\circ} \mathrm{C}$ with $4 \%$ paraformaldehyde in PBS. Dishes were washed three times for 10 min each in PBT (PBS plus $0.3 \%$ Triton X-100), followed by a 30 min wash in PBT+NGS (PBT with $10 \%$ normal goat serum). All washes were performed at room temperature. Cultures were incubated with primary antibodies in PBT+NGS for $12 \mathrm{hr}$ at $4^{\circ} \mathrm{C}$. The preabsorbed polyclonal rabbit anti- $\beta$ gal antiserum was used at 1:10000, and the mouse monoclonal antibody AD4.4 (generously provided by P. Hurban, Stanford University) against the EcR-B1 ecdysone receptor isoform (Talbot et al., 1993) was used at 1:10. The dishes were washed three times for 10 min each in PBT and once for $30 \mathrm{~min}$ in PBT+NGS. The cultures were incubated for $2 \mathrm{hr}$ at room temperature in the dark with secondary antibodies in PBT+NGS. The secondary antisera used were Cy3conjugated goat anti-rabbit at 1:667 and Cy2-conjugated donkey anti- 


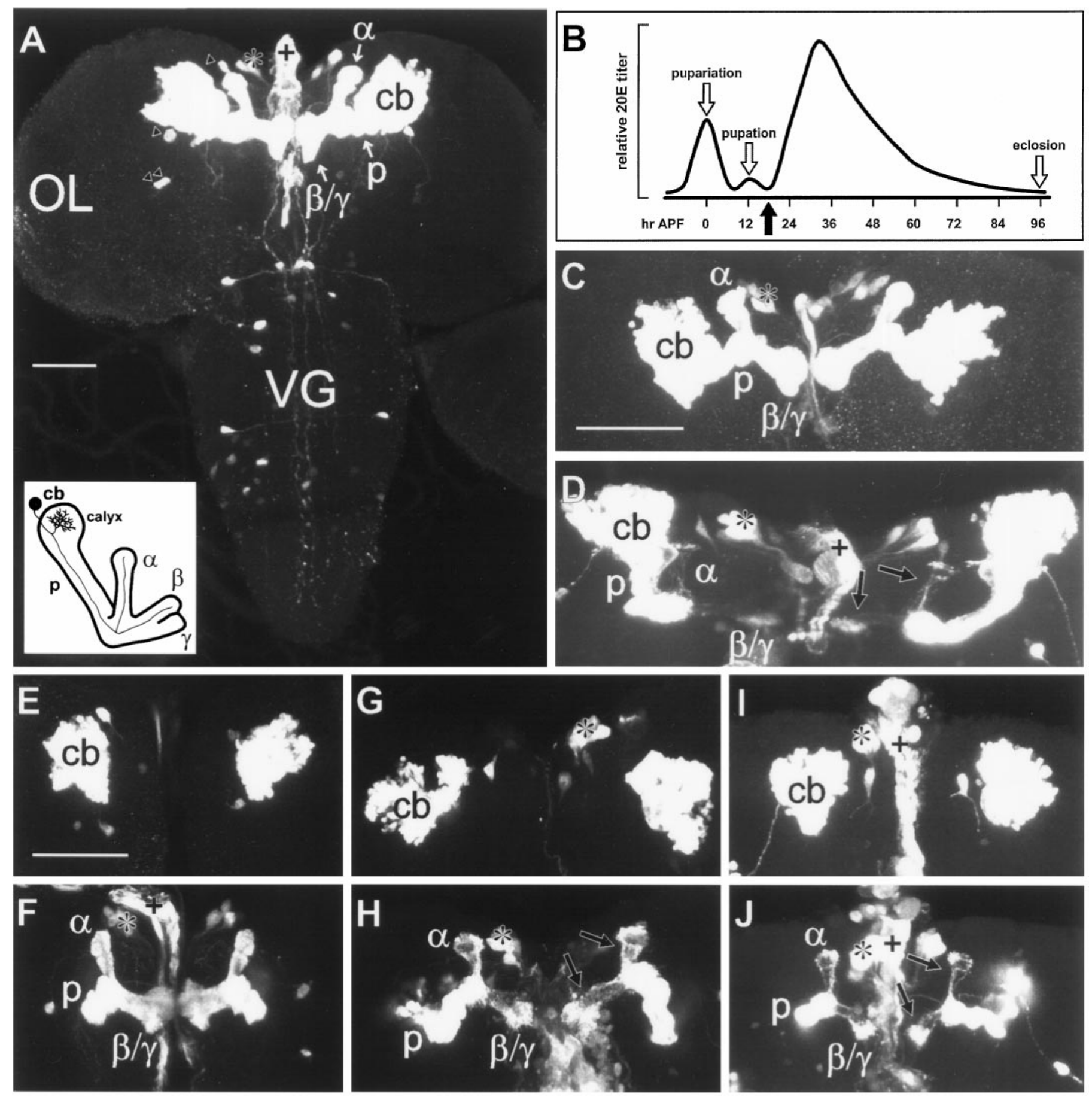

Figure 1. 201Y-directed reporter gene expression is restricted predominantly to the MBs during the larval-pupal transition. Confocal images of CNS whole mounts from $201 \mathrm{Y} \times \mathrm{UAS}_{\mathrm{G}}$-lac $Z$ larvae, prepupae, and early pupae that were immunostained to detect $\beta$ gal expression are shown. $A$, A third instar larval CNS displaying prominent staining within the symmetrically paired MBs, from the cell bodies $(c b)$, through the peduncle $(p)$, and into the dorsally directed $\alpha$ lobe and the medially directed $\beta$ and $\gamma$ lobes $(\alpha, \beta$, and $\gamma$, respectively). Anterior is toward the top of the figure. Staining is also seen in a few large neurosecretory cells of the pars intercerebralis $(*)$, located medially and anterior to the MBs, and in four additional neurons within each brain hemisphere (triangles). The pars intercerebralis neurons appear to send processes to the dorsal vessel, stained fragments of which are seen along the midline $(+)$. No $\beta$ gal expression is detected in the optic lobes $(O L)$. Additional neurons are stained in the ventral ganglion $(V G)$, but this region was excluded by dissection when establishing dissociated pupal cultures. Diagram, lower left corner, An oblique anterior view of an MB (adapted from Technau and Heisenberg, 1982; Yang et al., 1995). A single intrinsic neuron is depicted, showing the axonal projection into the lobes and the dendritic arbor within the calyx. B, Relative 20E titer during the larval-to-adult transition in Drosophila (adapted from Riddiford, 1993; Truman et al., 1994). A prominent ecdysteroid peak is detected at pupariation, marking the onset of metamorphosis. A small peak has been reported at pupation, $\sim 12 \mathrm{hr}$ (when reared at $25^{\circ} \mathrm{C}$ ) after puparium formation $(A P F)$, approximately coinciding with head eversion of the pupa. This is followed by a broad pupal peak of $20 \mathrm{E}$. The adult emerges at eclosion, $\sim 100 \mathrm{hr} A P F$. The dissociated cultures used in the experiments were prepared from brain tissue isolated 5-6 hr after head eversion (black arrow). $C$, Pupariation (see $B$ ), showing a projection of optical sections through the entire CNS. The distribution and intensity of staining are comparable with that seen in the $\mathrm{MB}$ of the third larval instar brain. $D$, An early pupal brain $5 \mathrm{hr}$ after head eversion (see $B$, black arrow), showing a projection of optical sections through the entire tissue. Note that staining within the lobes is substantially diminished (arrows). E-J, Pairs of confocal images, (Figure legend continues.) 
mouse (Amersham, Arlington Heights, IL) at 1:667. The dishes were then washed two times for $10 \mathrm{~min}$ each in PBT and two times for $10 \mathrm{~min}$ each in PBS in the dark. They were rinsed in $0.1 \mathrm{M}$ Tris-HCl, $\mathrm{pH} 8.0$, and mounted in PVA plus DABCO as described previously. This protocol was also used to simultaneously detect $\beta$ gal and EcR-B1 in CNS wholemount preparations, with the exception that the secondary antisera used were Cy2-conjugated donkey anti-rabbit at 1:1000 and Cy3-conjugated goat anti-mouse at 1:1000.

Data acquisition and analysis. Cultures double-labeled for the indirect immunofluorescent detection of $\beta \mathrm{gal}$ and neuronal membranes were observed under epifluorescence illumination with a Nikon Diaphot 300 inverted microscope (Nikon, Melville, NY) using $100 \times$ (for $2 \mathrm{~d}$ cultures) and $60 \times$ (for 3 and 4 d cultures) oil-immersion objectives (numerical aperture, 1.25 and 1.40 , respectively). The $\mathrm{Cy} 2$ signal was detected with bandpass filter set 41001 from Chroma Technology (Brattleboro, VT). A G-2A longpass filter set (Nikon) was used to visualize the LRSC signal. The anti- $\beta$ gal and anti-HRP ( $\alpha$ HRP) images were photographed with Kodak TMAX 400 Professional Film (Rochester, NY). Black and white photomicrographs (predominantly 8 inches $\times 10$ inches) of cells from each pair of culture dishes were printed by the same individual to ensure consistency.

For experiments 1 and 2, three pairs of dishes, each with a different culture time, were examined. The hormone status of each dish (with or without 20E) was unknown to the individual performing the search. Cultures were systematically screened, starting at the left margin of the well and proceeding to the right in an up-and-down sweep following the alphanumeric-labeled grid. All $\beta$ gal-positive neurons were noted, but only those for which all neurites appeared amenable to analysis were photographed. Cells were excluded when a branch could not be unambiguously followed because of the overlap of neurites from that cell or from neighboring cells. This was observed more frequently in older cultures in which neuritic outgrowth was most extensive and in rare instances of cell clumping. Each culture was surveyed until $\sim 50$ Bgalpositive neurons had been photographed. For experiments 1 and 2, an average of 55 and $86 \%$, respectively, of the surface area of each well was examined. Overall, $\sim 82 \%$ of all cells photographed could subsequently be analyzed, representing $\sim 55 \%$ of all $\beta$ gal-positive neurons encountered during the survey.

Measurements of total neurite length and branch number per neuron were performed by attaching photomicrographs of each cell to a digitizing tablet (Numonics Model 2210, Lansdale, PA) and tracing the neurites visualized by $\alpha$ HRP staining with a handheld cursor. The data were collected using SigmaScan measurement software (SPSS, Chicago, IL). The individual doing the measurements did not know whether a cell had been grown with or without $20 \mathrm{E}$. A branch was defined as a segment from the cell body or a branch point to a terminus and not as a segment between branch points. The total number of branches by this definition is equivalent to the "degree" or the number of terminal segments for a cell and is related to the number of branch points in that cell (Verwer and van Pelt, 1986; Uylings et al., 1989). Because no assumptions about segment order were made, this definition eliminated any bias that could be introduced by subjective decisions concerning which neurite to continue to follow at a branch point. The total neurite length and branch number for a cell were thus unaffected by the tracing paths chosen.

The length measurement of a branch was initiated at the margin of the cell body or neurite from which it emanated. Very short neurites (less than $\sim 8 \mu \mathrm{m}$ ) could not be measured reliably because of limitations in the precision of cursor placement at the ends of a measured segment. Furthermore, on Manduca motor neurons in vitro such short neurites are transient, actin-based filopodia that rarely contain microtubules (Matheson and Levine, 1999) that stabilize neuritic branches (Ahmad et al., 1993; Smith, 1994). Therefore, those neurites with a measured length $<7.8 \mu \mathrm{m}$ were not included in the length and branch number totals for a cell but were tallied separately. Adoption of this $7.8 \mu \mathrm{m}$ inclusion threshold minimized within-observer and between-observer measurement discrepancies. In a pilot study in which 46 cells were measured independently by two individuals using this criterion, an average difference in total neurite length of $4 \%$ and in branch number of $9 \%$ per cell was found. Nonetheless, all measurements within each experiment were performed by the same individual to maximize consistency. A statistical analysis found no consistent significant differences in the number of these short processes between cells grown with or without $20 \mathrm{E}$ across experiments, supporting the assumption that they are highly variable.

All cells measured were included in the statistical tests, which were performed using SigmaStat software (SPSS). The nonparametric MannWhitney rank sum test was used to assess the effect of hormone treatment on neurite length, branch number, and the relationship between branch number and total neurite length at each time point. The Pearson product moment correlation test was used to determine the correlation between branch number and total neurite length. All statistical analyses were performed at the default $\alpha$ level of 0.05 . In addition, branch number was plotted versus total neurite length for each cell, and a least-squares method was used to fit a straight line to the data with SigmaPlot (SPSS).

\section{RESULTS}

\section{$201 Y$ shows MB-selective expression in the brain during metamorphosis}

Drosophila MBs provide an ideal model for testing the role of $20 \mathrm{E}$ in metamorphic neuronal reorganization. Two large, densely packed, bilaterally symmetric clusters of MB neurons are located in the dorsal brain and can be identified using reagents specific for several molecular markers (Yang et al., 1995; Schulz et al., 1996). To test the response of pupal $\mathrm{MB}$ neurons to $20 \mathrm{E}$ in vitro, a reliable, specific marker was required to distinguish them from other neurons in primary dissociated cultures. We screened a number of P[GAL4] enhancer trap lines (Yang et al., 1995) for which MB-specific reporter gene expression in the adult brain had been documented. $\beta \mathrm{Gal}$ expression was examined in the late larval CNS of progeny of crosses between the reporter $\mathrm{UAS}_{\mathrm{G}^{-}}$lacZ and each of six P[GAL4] lines (30Y, 72Y, 201Y, c35, c739, and c747). At this time, the MBs contain 2200 Kenyon cells per side (Technau and Heisenberg, 1982; Technau, 1984). In all lines except 201Y, extensive reporter gene expression was seen outside the MB (data not shown). In the brain of 201Y larvae, strong expression of $\beta$ gal within the MBs was seen (Fig. $1 A$ ). The only non-MB cells marked by $\beta$ gal were a small cluster of large neurosecretory cells of the pars intercerebralis, which appear to project to the dorsal vessel, and four unidentified cells lateral to the $\mathrm{MB}$ in each brain hemisphere (Fig. $1 A$ ).

Reporter gene expression throughout the MBs of 201Y animals is extensive but is restricted to subsets of Kenyon cells. In addition, the pattern of $\beta$ gal staining in the peduncle and lobes appears somewhat different in larvae and adults. In the adult, expression is prominent in central elements of the $\alpha$ and $\beta$ lobes, as well as throughout the $\gamma$ lobe (Yang et al., 1995; Connolly et al., 1996). In contrast, the larval MBs reveal expression in outer elements of the lobes surrounding unstained central cores, and the $\alpha$ lobe terminates in a cap demarcated by an unlabeled collar (Fig. $1 A$; also see Fig. $1 F$ ) (Tettamanti et al., 1997). Because of these stage-specific differences and the observation that P[GAL4] lines exhibit dynamic expression patterns during development (Tettamanti et al., 1997), we needed to verify that 201Y-directed

\footnotetext{
depicting projections of optical sections through the cell body regions $(E, G, I)$ and the MB neuropils $(F, H, J)$ for each of three whole-mount preparations representing a developmental series. $E, F$, Pupariation (see $B, C)$. Note the stained cap and unstained collar of the $\alpha$ lobe and the unstained central cores of the lobes, similar to the pattern in the third instar larva (see $A$ ). $G, H$, Head eversion (pupation), $\sim 12 \mathrm{hr} A P F$ (see $B$ ). Relative to that at pupariation, staining within the lobes is reduced ( $H$, arrows), but cell body staining $(G)$ is similar. $I, J$, Head eversion plus $5 \mathrm{hr}, \sim 17 \mathrm{hr} A P F$ (see $B$, $D)$. Staining within the lobes $(J$, arrows) has diminished further, but cell body staining $(I)$ remains comparable with that seen at pupariation (see $E$ ) and pupation (see $G$ ). Scale bars: $A, 50 \mu \mathrm{m} ; C, D, 50 \mu \mathrm{m} ; E-J, 50 \mu \mathrm{m}$.
} 

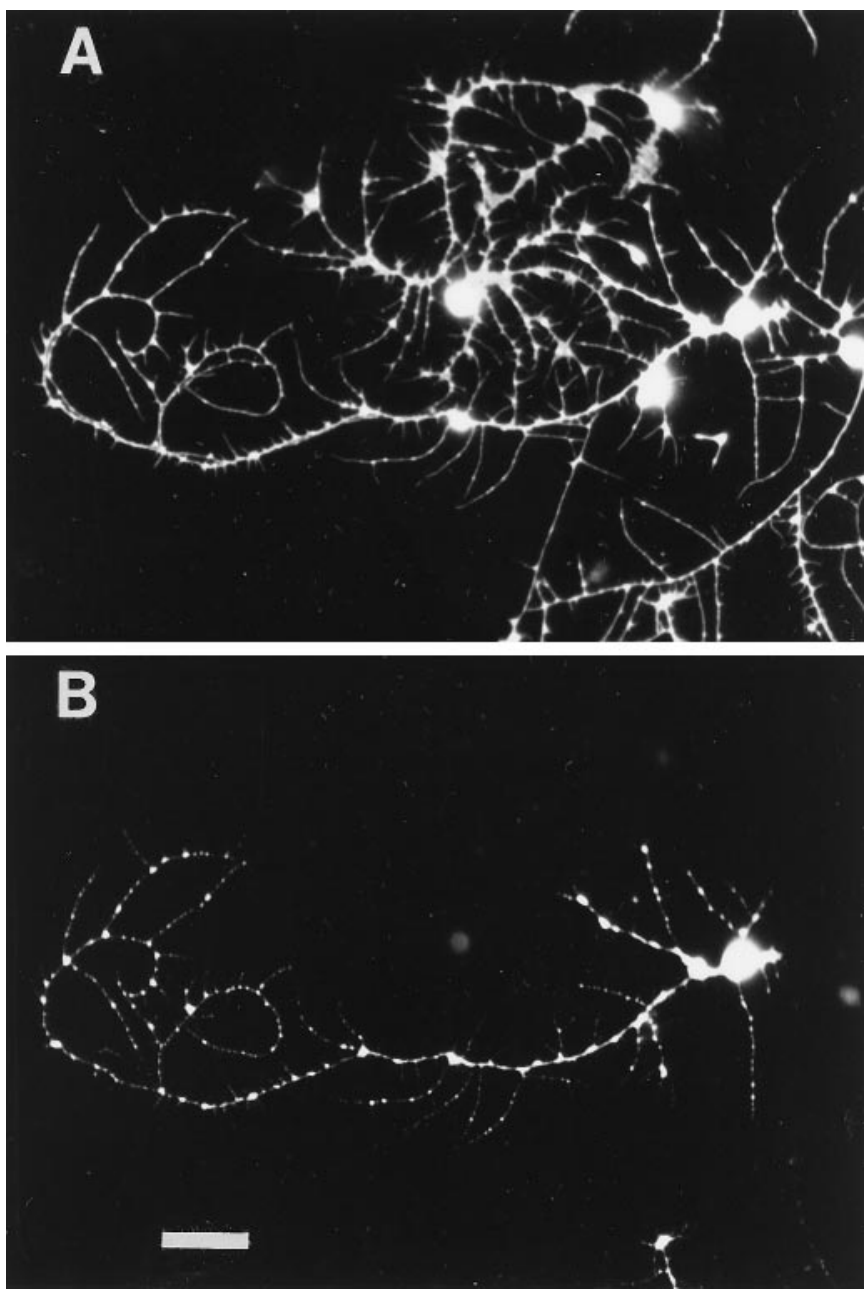

Figure 2. $\beta \mathrm{Gal}$ expression is restricted to a subset of neurons in primary cultures derived from $201 \mathrm{Y} \times \mathrm{UAS}_{\mathrm{G}}$-lacZ CNS tissue. $A, \alpha \mathrm{HRP}$ labeling of neuronal membranes in a fixed 4-d-old culture prepared from a pupal brain isolated $5 \mathrm{hr}$ after head eversion (see Fig. 1B) is shown. Four cell bodies and the complete neuritic arbors from three of those neurons are visible. $B, \beta \mathrm{Gal}$ is detected in the cell body and neuritic branches of only one of the four neurons shown in $A$, plus in a branch extending from a neuron outside the field. Scale bar, $20 \mu \mathrm{m}$.

reporter gene expression remains MB-selective during the larvalto-pupal transition.

As shown in Figure 1, $\beta$ gal expression remained highly restricted to the MBs in the brains of $201 \mathrm{Y} \times \mathrm{UAS}_{\mathrm{G}}$-lacZ prepupae and young pupae, with the exception of the few non-MB cells observed previously in the larva. The extent of 201Y-directed $\beta$ gal staining in the peduncle and lobes of the MB appeared similar in the third instar larva and the early prepupa (Fig. $1 A, C, F)$ but was reduced considerably within the lobes by pupation (Fig. $1 H$ ) and declined even more $5 \mathrm{hr}$ later (Fig. 1D,J). The reduction of labeling intensity in the neuropil is not accompanied by reduced labeling in the cell body region (Fig. $1 E, G, I$ ). This is consistent with the reduction in axon numbers without concomitant cell death observed by Technau and Heisenberg (1982) early during metamorphosis.

\section{Y provides a marker for Kenyon cells in dissociated cell cultures}

The 201Y CNS whole-mount staining patterns led to the expectation that reporter gene expression would distinguish a discrete population of neurons in heterogeneous primary cultures of which the vast majority would be Kenyon cells. Dissociated cell preparations of CNS tissue from larval and pupal progeny of $201 \mathrm{Y} \times \mathrm{UAS}_{\mathrm{G}}$-lacZ matings were cultured for periods of $2 \mathrm{hr}$ to $6 \mathrm{~d}$ in medium without 20E (see Materials and Methods). They were then fixed and stained to detect neuronal membranes and $\beta$ gal distribution. Cells observed $2 \mathrm{hr}$ after plating consisted primarily of a cell body and rarely had processes, indicating that most if not all neurites were lost during tissue dissociation. $\beta \mathrm{Gal}$ expression was detected in a subset of cells at this time (see below).

Cells grown for $4 \mathrm{~d}$ in culture typically had extensive neuritic trees as visualized by $\alpha$ HRP staining (Fig. $2 A$ ). The neuronal identity of all cells in culture at this time was confirmed by immunohistochemical staining for ELAV, a neuron-specific nuclear marker (Robinow and White, 1991) (data not shown). Cells expressing $\beta$ gal could easily be identified within the field of neurons (Fig. 2B). Many neurons were not $\beta$ gal-positive, and their representation reflected the size of the CNS region included in the dissociation (data not shown). As expected, $\beta$ gal-positive neurons made up the highest fraction of cells when the source material was restricted to the brain hemispheres encompassing the MBs (Fig. 2). Because the adult fly brain has $~ 5000$ Kenyon cells (Technau and Heisenberg, 1982; Technau, 1984), we estimate that the dissociation and plating protocol yielded a minimum $15-20 \%$ recovery of MB neurons. Because GAL4 expression is limited to a subset of Kenyon cells in 201Y animals (Yang et al., 1995) and because pupae have fewer Kenyon cells than adults have (Technau and Heisenberg, 1982), the actual recovery is probably higher.

\section{Pupal MB neurons express ecdysone receptors in vitro}

For MB neurons in culture to exhibit a cell-autonomous response to $20 \mathrm{E}$, they must express ecdysone receptors. The concentrations of the various Drosophila ecdysone receptor (EcR) isoforms within the $\mathrm{MB}$ neurons during metamorphosis fluctuate in a characteristic pattern (Truman et al., 1994). The EcR-B1 isoform is maximally expressed in the Kenyon cells at pupariation and then decreases but remains detectable for $40 \mathrm{hr}$ after puparium formation. Examination of EcR-B1 expression in brain whole mounts from $201 \mathrm{Y} \times \mathrm{UAS}_{\mathrm{G}}$-lacZ animals $5 \mathrm{hr}$ after pupation reveals that $\mathrm{MB}$ neuronal cell bodies marked by $\beta$ gal expression are positive for EcR-B1 expression (Fig. 3A,B). To determine whether EcR-B1 is also expressed in MB neurons isolated $5 \mathrm{hr}$ after pupation and dissociated into culture, we plated cells from brain and optic lobes of $201 \mathrm{Y} \times \mathrm{UAS}_{\mathrm{G}}-l a c Z$ animals for $2 \mathrm{hr}$ and then fixed and stained the cells to visualize $\beta g a l$ and EcR-B1. MB neurons identified by $\beta$ gal expression are invariably positive for EcR-B1, whereas EcR-B1 is also expressed in many, but not all, $\beta$ gal-negative neurons in the culture (Fig. $3 C, D$ ). This is consistent with whole-mount data demonstrating that EcR-B1 is expressed in Kenyon cells as well as in some other neurons of the CNS at this time during metamorphosis (Fig. $3 A$ ).

\section{$\alpha \mathrm{HRP}$ immunostaining faithfully reproduces the neuritic branches of Drosophila neurons in culture}

Because the MB neurons were identified after immunostaining for $\beta$ gal, measurements of branch number and total neurite length were performed on images of fixed cultured cells. To ensure that $\alpha \mathrm{HRP}$ immunostaining faithfully represented the living cell in culture, single neurons were photographed before fixation and again after indirect immunofluorescent staining (Fig. 

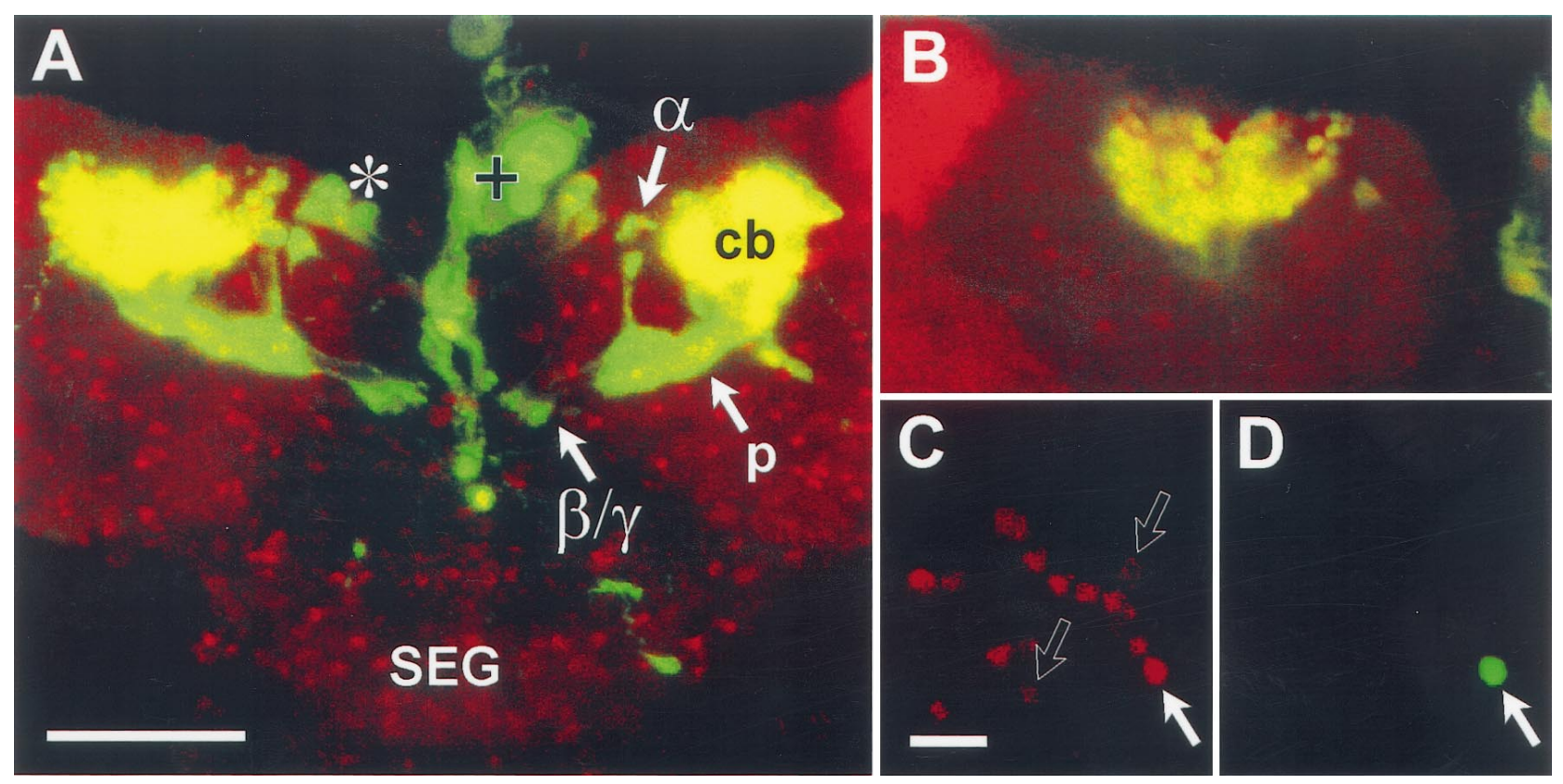

Figure 3. $\beta \mathrm{Gal}$-expressing Kenyon cells express ecdysone receptors in vivo and in vitro. Immunocytochemical staining to localize $\beta$ gal ( green) and the ecdysone receptor EcR-B1 isoform (red) in samples from $201 \mathrm{Y} \times \mathrm{UAS}_{\mathrm{G}}-l a c Z$ animals $5 \mathrm{hr}$ after pupation is shown. $A$, Confocal image showing a projection of optical sections through the entire brain. $\beta \mathrm{Gal}$ is evident in the cell body $(c b)$ region, peduncle $(p)$, and lobes $(\alpha$ and $\beta / \gamma)$ of the MBs, as well as in cells of the pars intercerebralis $\left(^{*}\right)$ and their processes extending to the dorsal vessel $(+)$. Nuclei of cells expressing EcR-B1 are scattered throughout the brain and the subesophageal ganglion $(S E G)$. The region of overlap, representing coexpression of $\beta$ gal and EcR-B1, is yellow and is localized to the cell body region of the MBs. $B$, A single optical section through the cell body cluster of the left MB in $A$, showing the colocalization of $\beta \mathrm{gal}$ and EcR-B1 in individual Kenyon cell somata. At this time during metamorphosis, there is a high level of EcR-B1 expression in cells of the optic lobe, evident by the intense red signal to the left. $C, D$ The identical field of cells in a $2 \mathrm{hr}$ culture prepared from the brain and optic lobes of a $201 \mathrm{Y} \times$ $\mathrm{UAS}_{\mathrm{G}}$-lac $Z$ animal $5 \mathrm{hr}$ after pupation and immunostained for EcR-B1 (red, C) and $\beta$ gal (green, D). A single cell ( filled arrow), corresponding to an MB neuron, expresses both $\beta$ gal and EcR-B1. In addition, $\beta$ gal-negative cells can be seen that are positive for EcR-B1 expression with various levels of intensity $(C)$. There are also cells that appear to be negative for both $\beta$ gal and EcR-B1 expression (open arrows). Scale bars: $A, B, 50 \mu \mathrm{m} ; C, D, 10 \mu \mathrm{m}$.
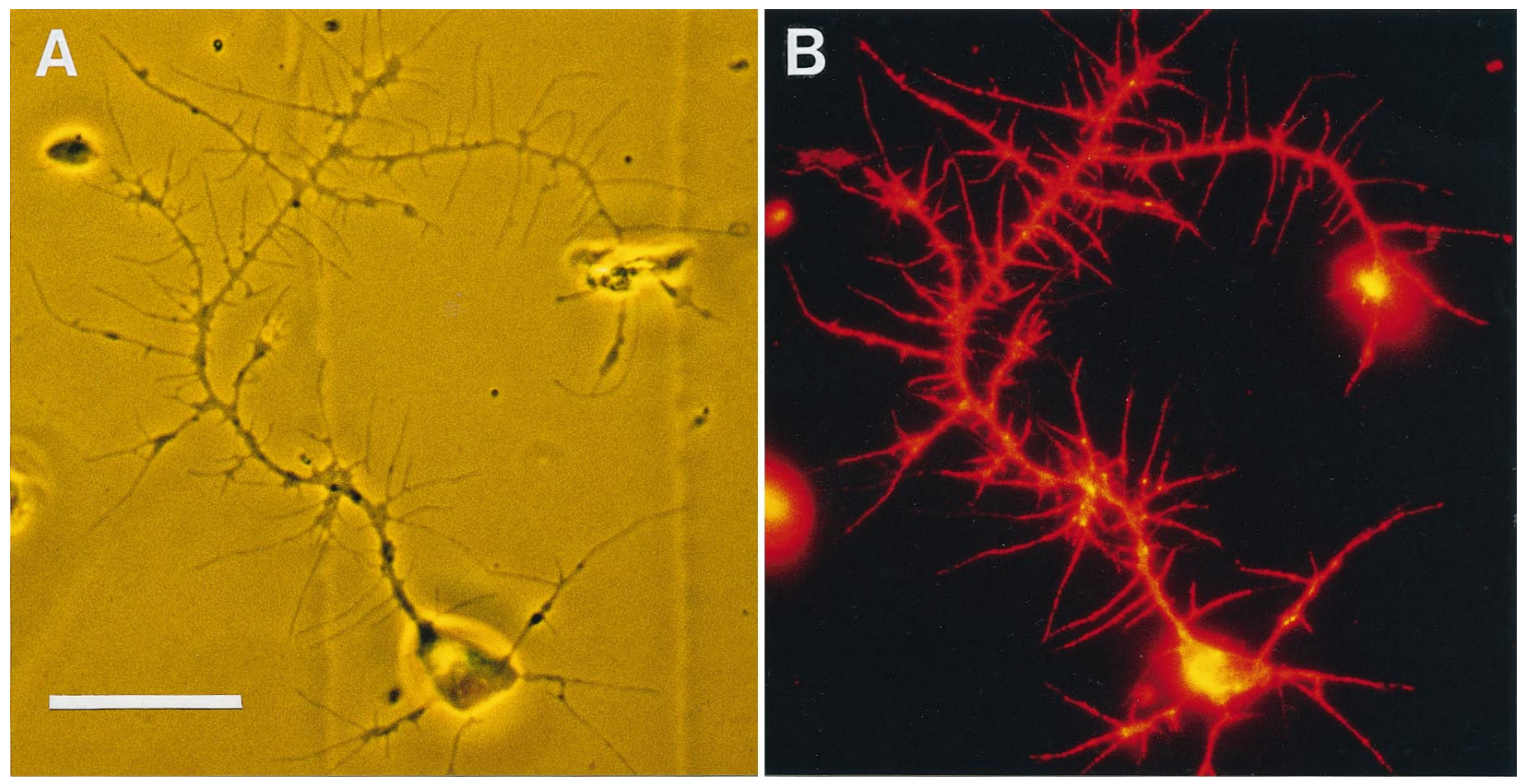

Figure 4. $\alpha \mathrm{HRP}$ immunostaining of fixed Drosophila neurons in culture faithfully reproduces the neuritic branches of the live cell. $A$, Phase-contrast image of a live neuron that has grown for $5 \mathrm{~d}$ in a dissociated culture prepared from $201 \mathrm{Y} \times \mathrm{UAS}_{\mathrm{G}}-$ lac $_{\mathrm{w}}$ whole larval CNS. $B, \alpha \mathrm{HRP}$ staining (Lissamine Rhodamine, red) of the neuron depicted in $A$ after fixation. Scale bar, $20 \mu \mathrm{m}$. 

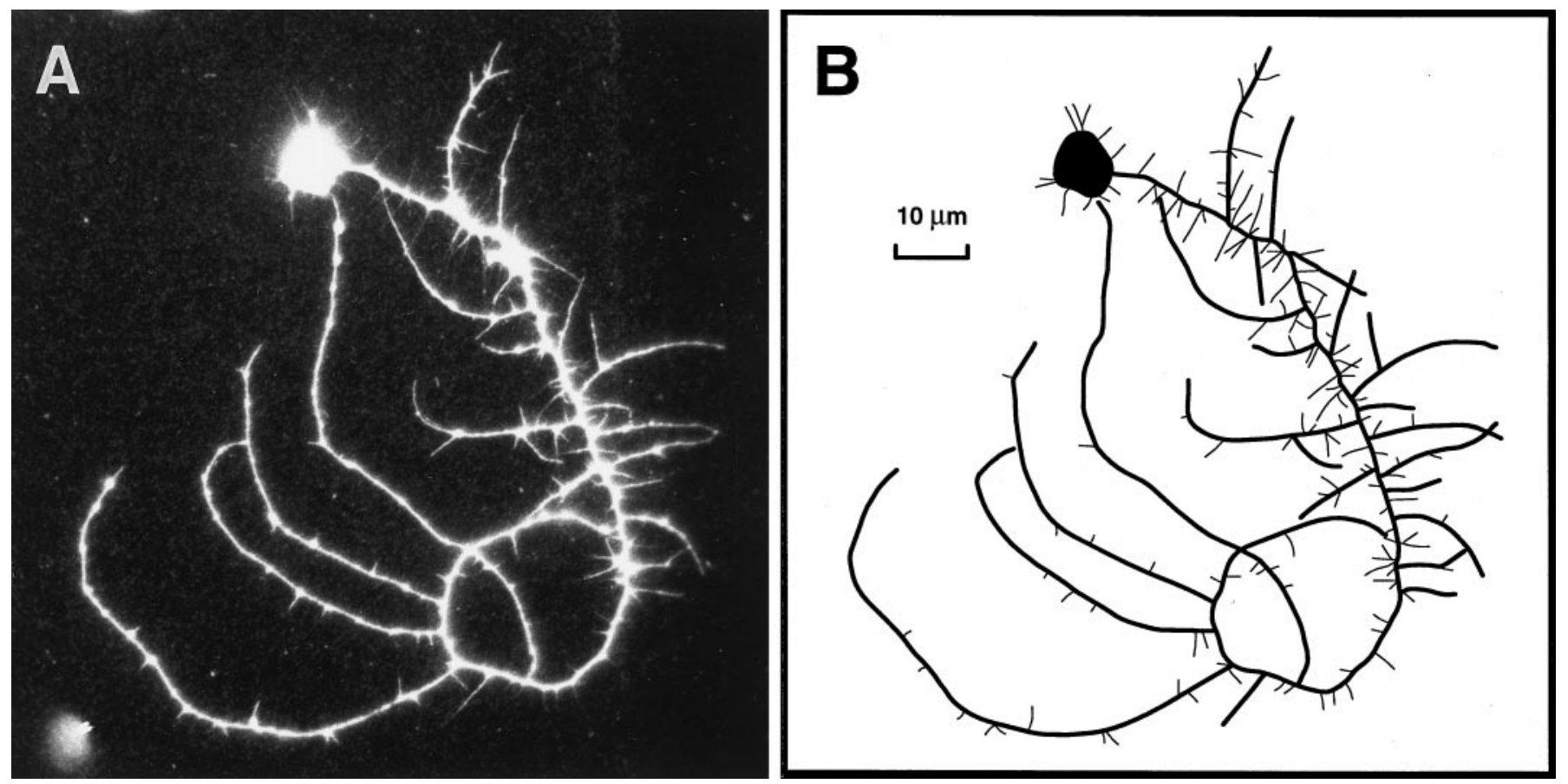

Figure 5. A representative example illustrating the morphometric approach used to analyze pupal MB neurons in vitro. A, $\alpha \mathrm{HRP}$ immunostaining of a $\beta$ gal-positive cell identified in a $3 \mathrm{~d}$ culture from experiment 1 . Such black and white photomicrographs were used to make measurements. $B$, A line drawing depicting how the neuron in $A$ was interpreted for this study. The thick lines represent neuritic branches with a measured length of $7.8 \mu \mathrm{m}$ or greater that were included in the total neurite length measurement $(735 \mu \mathrm{m})$ and branch number tally $(25)$ for this cell. The thin lines represent branches with measured lengths $<7.8 \mu \mathrm{m}$, of which there were 144 (see Materials and Methods).

4). All the neuritic branches visible on the live cell are reproduced in the fluorescent image, as clearly demonstrated by comparing the phase-contrast image of the live neuron (Fig. $4 A$ ) with the same cell fixed and labeled with $\alpha$ HRP primary and LRSCconjugated secondary antiserum (Fig. 4B). Figure 5 illustrates an example of how neuronal morphology was interpreted in this study. The cell depicted is an MB neuron cultured for $3 \mathrm{~d}$ in the presence of $20 \mathrm{E}$. The thick lines in the diagram (Fig. $5 B$ ) represent branches measured from the $\alpha \mathrm{HRP}$-stained image (Fig. $5 A$ ) with lengths of $7.8 \mu \mathrm{m}$ or greater. These branches were included in total branch number and total neurite length measurements for the cell. This Kenyon cell had 25 branches with a total neurite length of $735 \mu \mathrm{m}$. The thin lines represent 144 neurites with lengths of $<7.8 \mu \mathrm{m}$ that were not included in the total branch number or total neurite length (see Materials and Methods).

\section{E enhances total neurite length and branch number of pupal MB neurons in vitro}

The demonstration that $201 Y$ was a suitable marker for Kenyon cells in culture and that $\alpha \mathrm{HRP}$ immunostaining provided an accurate representation of neuronal morphology fulfilled conditions essential to permit the morphometric analysis of the in vitro response of pupal MB neurons to 20E. Two small-scale pilot studies suggested that early pupal Kenyon cells from $201 \mathrm{Y} \times$ $\mathrm{UAS}_{\mathrm{G}}$-lacZ brain tissue cultured with $20 \mathrm{E}$ for $3 \mathrm{~d}$ did exhibit significantly greater total neurite length and branch number compared with that in untreated cells (data not shown). Thus, two comprehensive independent experiments (1, female, and 2, male) were performed to confirm and expand those results. For each experiment, regionally dissected brain tissue from a single animal was isolated $5 \mathrm{hr}$ after pupation (see Fig. $1 B$ ) and dissociated into three pairs of culture dishes. When the dishes were flooded with medium $2 \mathrm{hr}$ after plating, one dish from each pair received medium containing $1 \mu \mathrm{g} / \mathrm{ml} 20 \mathrm{E}\left(2.1 \times 10^{-6} \mathrm{M}\right)$. This concentration of $20 \mathrm{E}$ has been shown to elicit a significant response by Manduca motor neurons in culture (Prugh et al., 1992; Matheson and Levine, 1999) and is within the physiological range estimated to occur in vivo during metamorphosis in Drosophila (Fristrom and Fristrom, 1993). Whether hormone was in a dish was unknown to the individual who scanned them for $\beta$ gal-expressing MB neurons and who later performed the measurements on the photographic images of those cells. The paired dishes were cultured for 2, 3, or $4 \mathrm{~d}$. The results of the two experiments are summarized in Figure 6.

Kenyon cells isolated from Drosophila early pupal CNS and cultured in vitro exhibited enhanced process outgrowth when exposed to $20 \mathrm{E}$, manifested by greater total neurite length (Fig. $6 A, B)$ and increased branch number (Fig. $6 C, D$ ). The difference in total neurite length between cells grown with or without $20 \mathrm{E}$ was significant by $3 \mathrm{~d}$ for experiment 1 , and this difference persisted at $4 \mathrm{~d}$ (Fig. $6 A$ ). A significant difference in total neurite length between the two treatment groups was evident by $2 \mathrm{~d}$ for experiment 2, and this difference persisted at 3 and $4 \mathrm{~d}$ (Fig. 6B). Similarly, in both experiments branch number was significantly different between cells grown with or without $20 \mathrm{E}$ by $3 \mathrm{~d}$ in culture, and this difference persisted at $4 \mathrm{~d}$ (Fig. 6C,D). Nonetheless, 20E was not essential for growth of Kenyon cells in culture, because the mean total neurite length and branch number of untreated cells did increase over time, but to a significantly lesser extent than that for the hormone-treated cells.

Figure 7 illustrates the changes in neuronal size within Kenyon cell populations over time in vitro in the presence or absence of 20E. The data shown are from experiment 1 and reflect the trend 

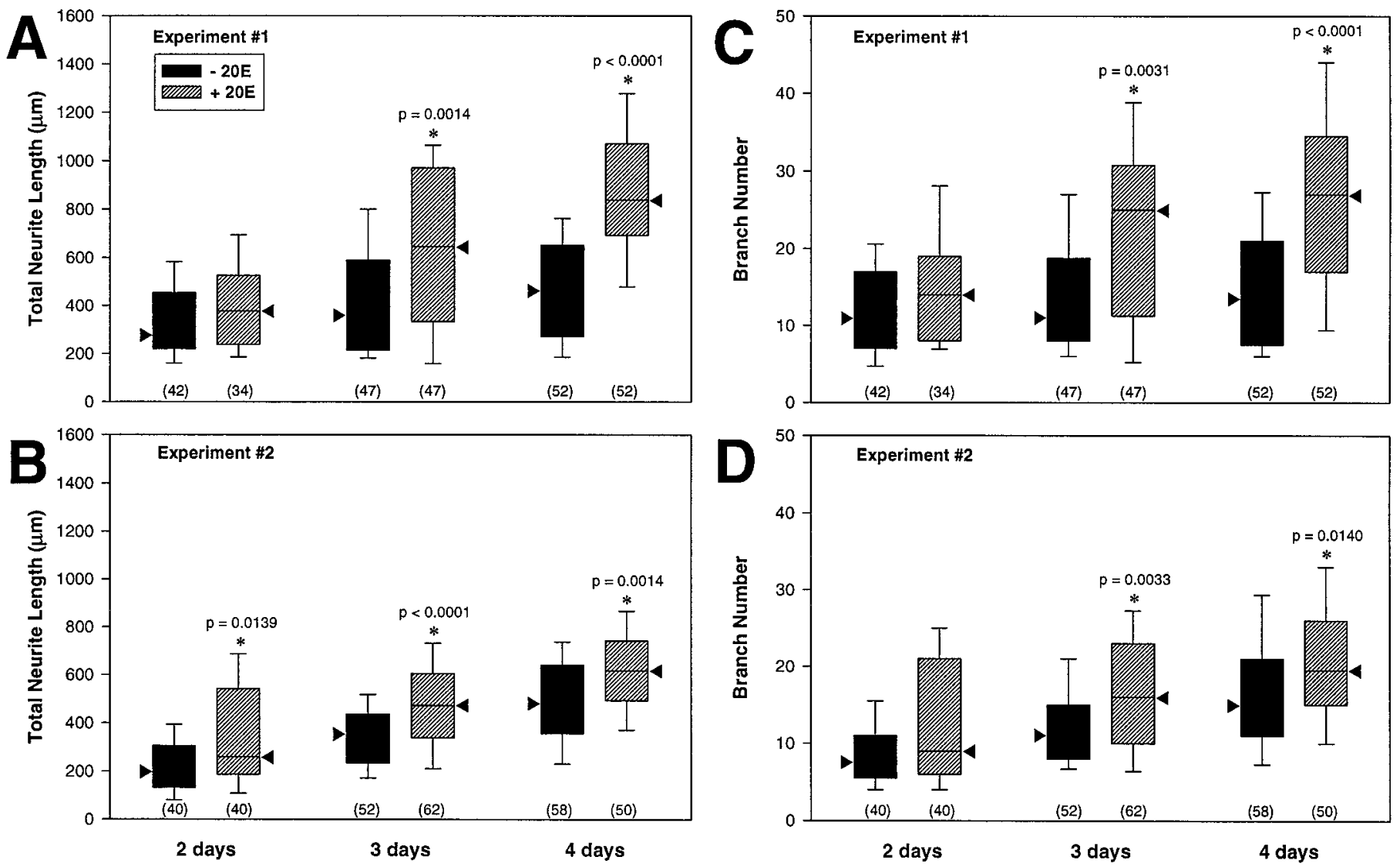

Figure 6. Drosophila pupal MB neurons grown in culture exhibit significantly greater total neurite length and branch number in response to 20E. The box plots show the distributions for total neurite length $(A, B)$ and branch number $(C, D)$ for cells grown without (black) or with (hatched) $20 \mathrm{E}$ for 2 , 3 , or $4 \mathrm{~d}$ in experiments $1(A, C)$ and $2(B, D)$. The black triangles mark the median values, the boxes represent the 25th and 75th percentile limits, and the bars indicate the 10th and 90th percentile limits. The number of cells included in each data set is shown within parentheses below the plots. The data in $A$ and $C$ represent measurements from the identical cells for experiment 1, as does the data in $B$ and $D$ for experiment 2 . Statistically significant differences between treatments on any given day as determined by the Mann-Whitney rank sum test are indicated $\left(^{*}\right)$ along with the corresponding $p$ value. For total neurite length, significant differences between treatments were found at 3 and $4 \mathrm{~d}$ for experiment $1(A)$ and at all three time points for experiment $2(B)$. For branch number, significant differences were found between cells grown with and without $20 \mathrm{E}$ at 3 and $4 \mathrm{~d}$ for both experiments.

seen in experiment 2. Histograms depicting total neurite length (Fig. $7 A$ ) and branch number (Fig. $7 B$ ) at 2,3, and 4 d show that the population distributions representing the two treatment groups overlap at all time points. However, although the treated and untreated populations were similarly distributed at $2 \mathrm{~d}$, they diverged considerably by $4 \mathrm{~d}$. The cell populations cultured without $20 \mathrm{E}$ did show increasing size (both length and branch number) over time, but the dishes cultured with $20 \mathrm{E}$ had many more large cells, suggesting that $20 \mathrm{E}$ enhanced the growth of $\mathrm{MB}$ neurons.

\section{The relationship between branch number and total neurite length remains constant for Kenyon cells in culture regardless of treatment}

Manduca pupal motor neurons respond to $20 \mathrm{E}$ in vitro by increased branching at growth cones (Matheson and Levine, 1999), resulting in increased branch complexity (Prugh et al., 1992). To determine whether 20E also influences branch complexity of cultured Drosophila pupal Kenyon cells, we examined the relationship between branch number and total neurite length of individual cells grown in the presence or absence of 20E. Figure 8 depicts the branch number and total neurite length for each cell from experiment 1 for both treatments on each day. The ratios of branch number to total neurite length and total neurite length to branch number did not differ significantly between hormone treatment groups. The median values for these ratios were surprisingly constant regardless of treatment over all $3 \mathrm{~d}$, with branch number per $100 \mu \mathrm{m}$ ranging from 3.1 to 3.7 and length per branch ranging from 28 to $32 \mu \mathrm{m}$ for experiment 1 . Experiment 2 results were comparable (data not shown). Application of the Pearson product moment correlation test showed that there was a significant positive correlation between branch number and total neurite length, with correlation coefficient values ranging from 0.74 to 0.95 .

The constancy of the relationship between branch number and total length, regardless of time in culture, became particularly apparent when a straight line was fit to the data from each population using the least-squares method (Fig. 8). Furthermore, exposure to $20 \mathrm{E}$ seemed to have no effect on this relationship. This was particularly evident for the $4 \mathrm{~d}$ cells, in which the two populations had diverged in range but nonetheless were arrayed to yield linear relationships with very similar slopes. This analysis demonstrates that cells with a given total neurite length tend to have similar branch numbers, whether or not they have been exposed to hormone. $20 \mathrm{E}$ does not alter the quantitative relationship between branch number and total length, nor does it have an obvious qualitative effect on the shape of MB neuronal arbors. Rather, 20E enhances the overall extent of process outgrowth, 

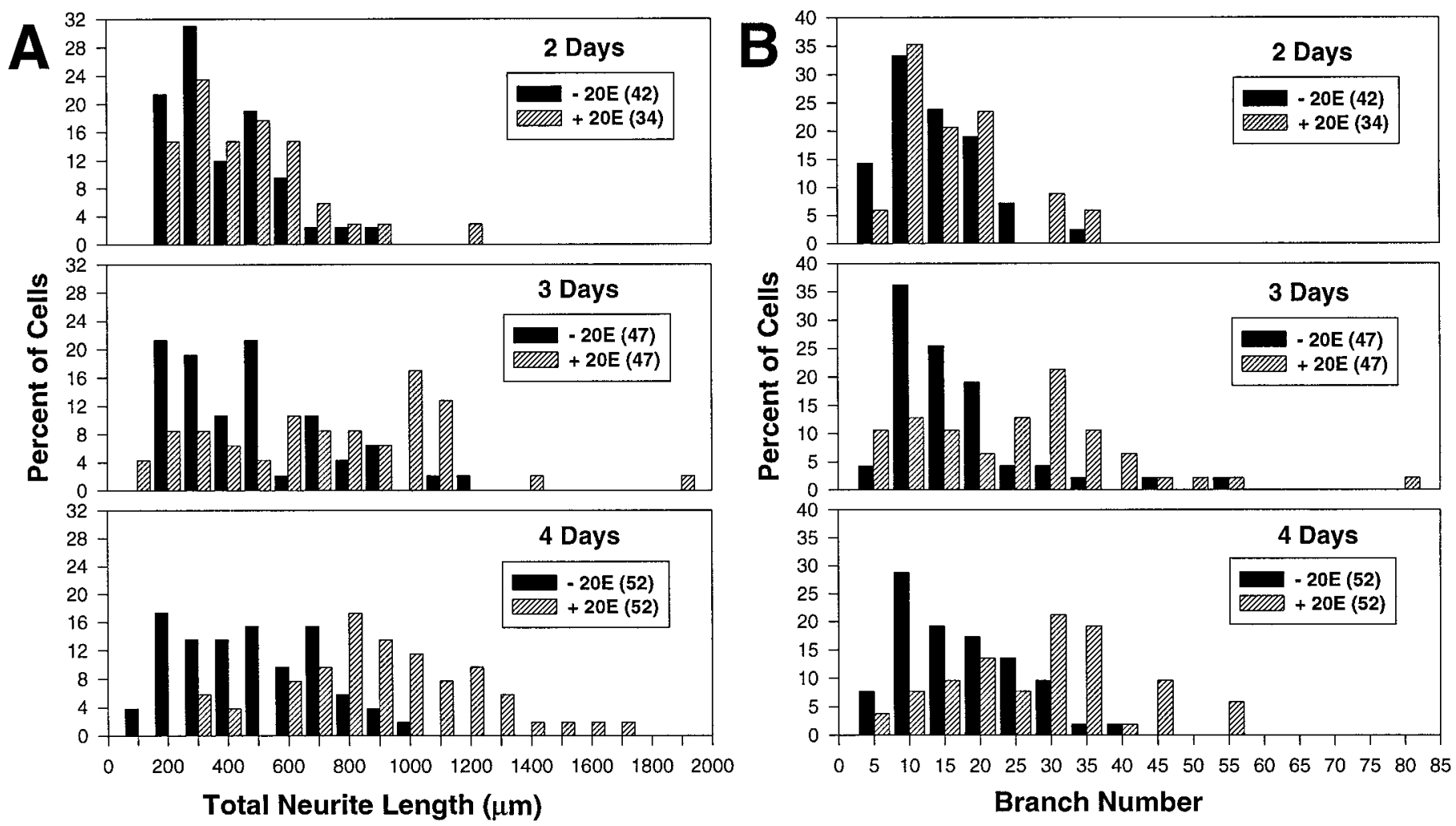

Figure 7. Histograms depicting the distributions of total neurite length $(A)$ and branch number $(B)$ for pupal MB neurons grown in culture without (black) or with (hatched) $20 \mathrm{E}$ at 2,3, and $4 \mathrm{~d}$ (experiment 1). The number of cells included in each group is indicated in parentheses in the legends. $A$, The percentage of MB neurons for each treatment with total neurite lengths up to and including $100 \mu \mathrm{m}$ and every $100 \mu \mathrm{m}$ increment thereafter. The length distributions for untreated and hormone-treated cells are almost identical at $2 \mathrm{~d}$, but by $4 \mathrm{~d}$ the distributions have diverged considerably, suggesting an enhanced rate of growth in response to $20 \mathrm{E}$. $B$, The percentage of MB neurons for each treatment with branch numbers up to and including 5 and every increment of 5 after that. Again, branch numbers for the two cell populations are similarly distributed at $2 \mathrm{~d}$, but by $4 \mathrm{~d}$ the distributions have diverged, reflecting enhancement by $20 \mathrm{E}$.

increasing total neurite length and branch number proportionately and not selectively influencing the tendency to form new branches. Taken together, the data suggest that $20 \mathrm{E}$ increases the rate of MB neurite outgrowth in vitro.

\section{MB neurons display a characteristic morphology in vitro}

Pupal Kenyon cells growing in vitro exhibited a striking polar morphology, with most if not all branches arising from one primary neurite (see Figs. 2, 5). In contrast, $\beta$ gal-negative neurons, the majority of which are not Kenyon cells, were much more likely to assume a stellate appearance (Fig. $2 A$ ). To quantify this feature, a polarity index, equal to the maximum percentage of total neurite length contributed by a primary neurite and all of its branches, was calculated for each $\beta$ gal-positive cell that was analyzed. A monopolar neuron would have a polarity index of 100. Figure 9 summarizes the polarity indices for the MB neurons in the $4 \mathrm{~d}$ cultures from experiment 1 . The majority of Kenyon cells displayed a high degree of polarity, with over $80 \%$ of their total neurite length found in a major primary neurite and its associated arbor. There was no significant difference between the polarity indices of cells grown in the presence or absence of $20 \mathrm{E}$, consistent with the conclusion that hormone treatment does not alter qualitative features of MB neuron morphology.

Four MB neurons representing different points along the polarity index spectrum are shown in Figure 10. A few cells could best be described as stellate, with no obvious polarity and a correspondingly low polarity index (Fig. 10A). Some cells possessed several large primary neurites, with a moderate polarity index (Fig. 10B). Most MB neurons, however, had a high polarity index, with a major dominant primary neurite and one or two additional shorter primary neurites (Fig. 10C), or were monopolar, with all of the total neurite length invested in a single primary neurite and its branches (Fig. 10D). This consistent cell morphology typified the majority of Kenyon cells in vitro and is remarkably similar to the shape they assume within adult $\mathrm{MBs}$ in vivo (Yang et al., 1995), suggesting that MB neurons have an intrinsic propensity to grow in a stereotypical manner to generate a dominant primary neurite.

\section{DISCUSSION}

\section{Pupal MB neurons respond to 20E in vitro}

Several lines of evidence indicate that the MBs undergo considerable reorganization during Drosophila metamorphosis. These include the reduction and subsequent increase in axon number within the peduncle (Technau and Heisenberg, 1982), mutants with $\mathrm{MB}$ anatomical phenotypes that become apparent during metamorphosis (Technau and Heisenberg, 1982), and P[GAL4] lines with different MB expression patterns in larvae and adults (Tettamanti et al., 1997). As in other insects (Strausfeld et al., 1995), the MBs of adult Drosophila are essential components of the neural pathway that mediates associative learning (Heisenberg et al., 1985; de Belle and Heisenberg, 1994; Connolly et al., 


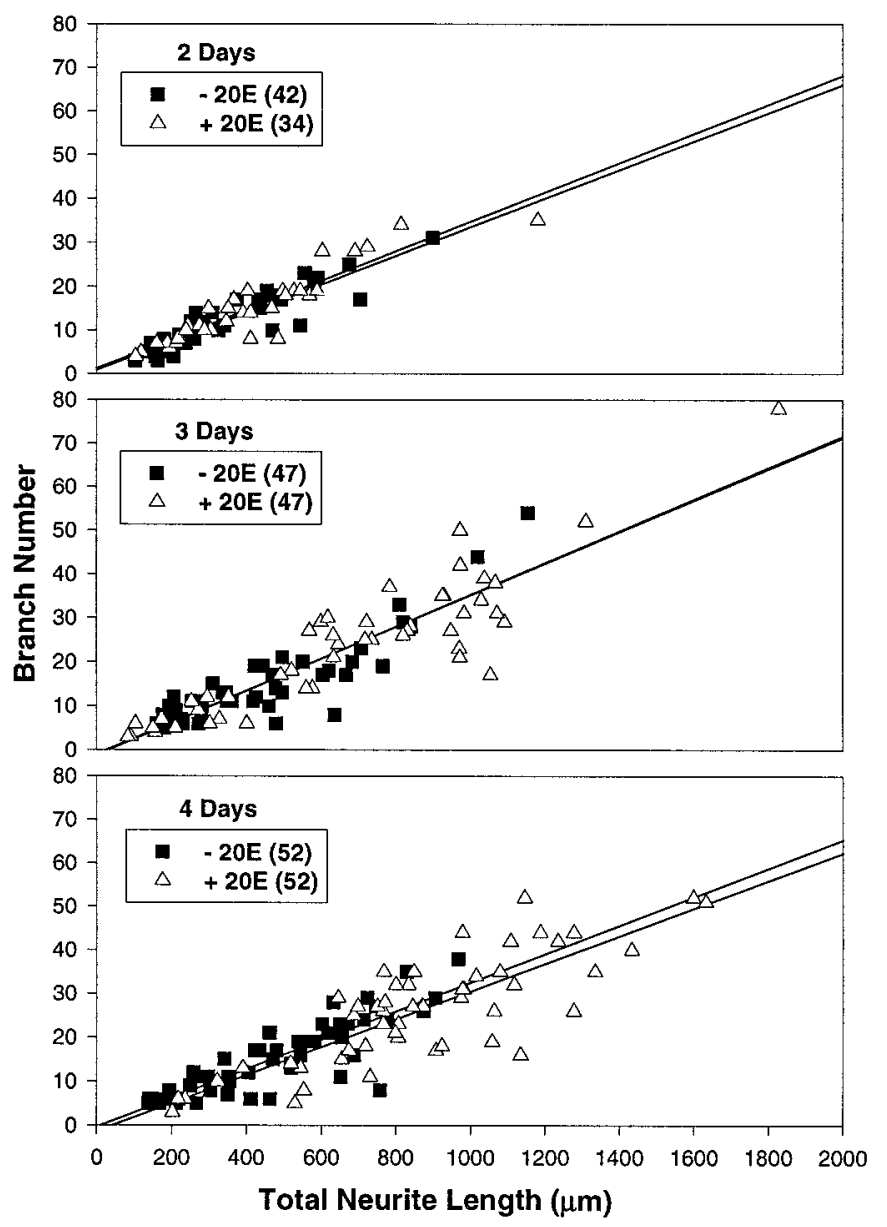

Figure 8. The relationship between branch number and total neurite length of individual pupal MB neurons remains constant over time in culture and is not affected by exposure to $20 \mathrm{E}$. Each cell from experiment 1 was plotted by branch number and total neurite length. Untreated neurons are represented as $\mathbf{\square}$, and hormone-treated neurons are represented as $\triangle$. The number of cells included in each group is indicated in parentheses in the legends. Straight lines were fit to each set of data points by the least-squares method. The slopes of the lines are 0.033 and 0.034 at $2 \mathrm{~d}, 0.036$ and 0.036 at $3 \mathrm{~d}$, and 0.033 and 0.032 at $4 \mathrm{~d}$ for cells grown in the absence and in the presence of $20 \mathrm{E}$, respectively.

1996). Experience-dependent neuroanatomical plasticity in the MBs has also been demonstrated during adult life (Technau, 1984; Balling et al., 1987; Heisenberg et al., 1995; Barth and Heisenberg, 1997). Therefore, studying Kenyon cell development during the pupal period, when adult MB organization is initially established, should contribute to understanding the mechanisms that generate the neuronal architecture required for learning and memory.

We have shown that pupal MB neurons exhibited significantly greater total neurite length and branch number when cultured in vitro in the presence of physiological levels of 20E. This response is consistent with our hypothesis of a critical role for $20 \mathrm{E}$ in supporting axonal regeneration within the MBs during pupal development in vivo. The available evidence suggests that the growth enhancement we observed was not caused simply by improved neuronal health in the presence of $20 \mathrm{E}$ in vitro. First, the MB neurons survive and extend neurites in the absence of $20 \mathrm{E}$, indicating that basal culture conditions are not limiting. Second, in vitro studies in Manduca, performed with similar

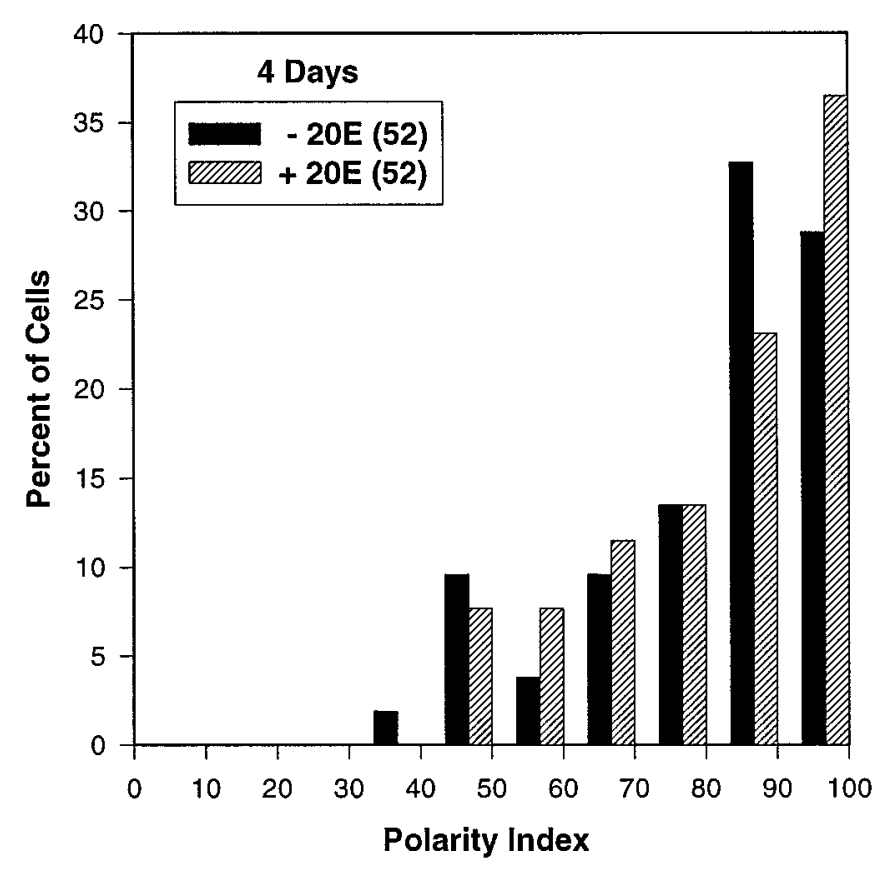

Figure 9. The polarity index distributions for pupal MB neurons from the $4 \mathrm{~d}$ cultures of experiment 1 demonstrate that the majority of Kenyon cells in vitro display a highly polar morphology, regardless of hormone treatment. The histograms depict the percentage of MB neurons for each treatment (without $20 \mathrm{E}$, black; with $20 \mathrm{E}$, hatched) with polarity index values falling within intervals of 10 . The polarity index is equal to the maximum percent of total neurite length in a primary process and all branches arising from it. The number of cells included in each group is indicated in parentheses in the legend.

methodology, demonstrate that the cell culture system can faithfully replicate the cellular specificity of hormonal responses seen in the intact animal. For instance, the response of thoracic motor neurons to $20 \mathrm{E}$ depends on their developmental stage both in vivo (Kent and Levine, 1993) and in vitro (Prugh et al., 1992). Similarly, 20E can induce neuron death in vitro with the same segment specificity (Streichert et al., 1997) that is seen in vivo (Weeks and Ernst-Utzschneider, 1989).

Expression of EcR by the pupal Kenyon cells in vitro suggests that the response of these dissociated neurons to $20 \mathrm{E}$ is mediated via transcriptional regulation of one or more genetic pathways (Richards, 1997) and that this may be occurring in a cellautonomous manner. However, the presence of numerous EcRpositive generic brain neurons in the cultures allows for the possibility that the influence of $20 \mathrm{E}$ on Kenyon cells is indirect, perhaps requiring secreted factors from other neurons. In any case, responsiveness to $20 \mathrm{E}$ is unlikely to be unique to $\mathrm{MB}$ neurons because many other neurons express EcR both in vivo and in vitro. The likely targets of $20 \mathrm{E}$ action during early pupal development include other larval neurons that are re-elaborating processes (Vallés and White, 1988; Truman, 1990) and newly born imaginal neurons (Ito and Hotta, 1992) that are generating processes de novo.

\section{E enhances neuronal size but not branch complexity}

The enhanced outgrowth exhibited by pupal MB neurons in response to $20 \mathrm{E}$ in vitro was proportional, in that the ratio of branch number to total neurite length remained constant regardless of hormone treatment and time in culture. This is consistent with an effect of $20 \mathrm{E}$ on the rate of neurite outgrowth. To confirm 

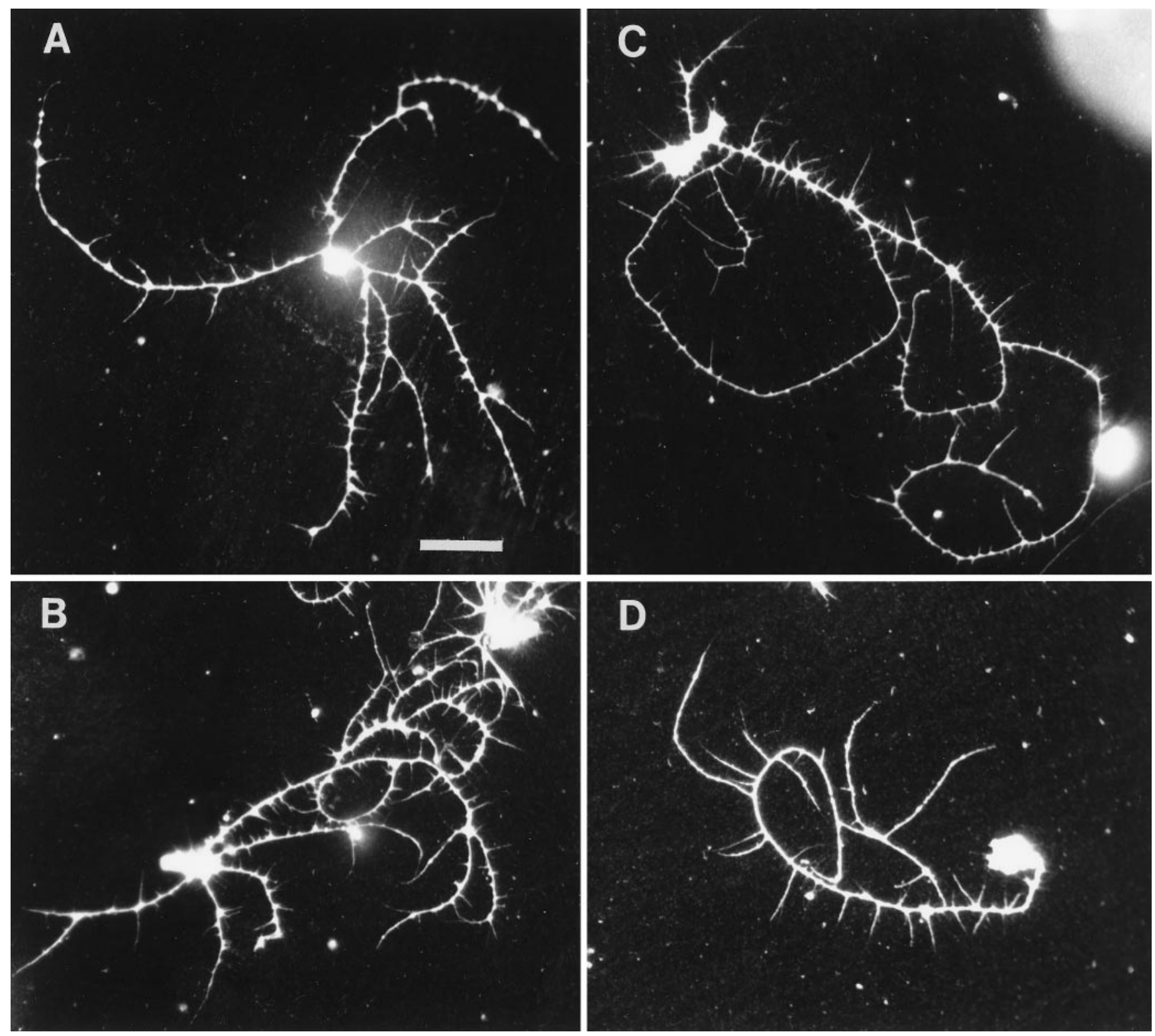

Figure 10. Pupal MB neurons from the $3 \mathrm{~d}$ cultures of experiment 1, illustrating the range in morphologies exhibited by Kenyon cells in vitro. A, Polarity index $=49$ (note the stellate morphology). $B$, Polarity index $=67 . C$, Polarity index $=86 . D$, Polarity index $=100$ (this is a monopolar neuron). Scale bar, $20 \mu \mathrm{m}$.

this interpretation, it will be necessary to identify individual Kenyon cells shortly after plating and then to follow their growth over time. This can be done by using the GAL4-UAS system to direct expression of a suitable marker (Brand, 1995). Such methods could also resolve questions concerning the origin, stability, and fate of short and long branches.

The enhanced growth of pupal MB neurons in response to $20 \mathrm{E}$ was more robust in experiment 1 , which used female brain tissue, than in experiment 2, which used male tissue. Similar gender differences have been seen in other experiments not presented here (Kraft, unpublished observations). This observation raises the possibility that sexual dimorphism, demonstrated previously for Kenyon cell fiber number (Technau, 1984) and impact on courtship behavior (Ferveur et al., 1995; O’Dell et al., 1995), also exists for the response of $\mathrm{MB}$ neurons to $20 \mathrm{E}$ during metamorphosis.

Our data indicate that $20 \mathrm{E}$ changes the rate, but not the mode, of Kenyon cell growth. Hence, 20E does not affect branch complexity of cultured Drosophila pupal MB neurons. This contrasts with Manduca motor neurons, which respond to 20E by increased branching at growth cones (Matheson and Levine, 1999). The difference may reflect cell type-specific, hormone-dependent growth responses that fulfill the distinct requirements of these two neuronal populations during metamorphosis. Whereas Manduca motor neurons elaborate extensive dendritic and axonal arbors to make new synaptic connections (Kent and Levine, 1988, 1993; Consoulas et al., 1996), Drosophila Kenyon cells must extend regenerating axons over a considerable distance to reach synaptic targets in the lobes. We propose that $20 \mathrm{E}$ provides a signal for accelerated growth of MB neurons so that they can accomplish this within the $90 \mathrm{hr}$ of pupal development and thereby establish the circuitry necessary for experience-dependent adult behavior.

Recent advances in understanding the control of neuronal 
growth provide some clues as to the downstream molecular mediators of the $20 \mathrm{E}$ effect on pupal Kenyon cells. At a fundamental level, neurite outgrowth and branching require membrane addition, cytoskeletal extension and reorganization, and interaction with the substrate, processes that may be interdependent (Tanaka and Sabry, 1995; Futerman and Banker, 1996; Baas, 1997; Caroni, 1997). For example, recent studies have focused on the role of Rho family GTPases in transducing extracellular signals into a neuritic growth response via reorganization of the actin cytoskeleton (Mackay et al., 1995; Luo et al., 1997; Gallo and Letourneau, 1998; Hall, 1998). We can now test the consequences of disrupting specific signaling pathways by using the GAL4-UAS system (Brand and Perrimon, 1993) to express dominant-negative or constitutively active forms of candidate molecules in Kenyon cells from 201Y animals.

\section{The Kenyon cell culture system}

In vitro cell culture systems have proven indispensable for investigating development and plasticity of vertebrate and invertebrate neurons (Beadle et al., 1988; Banker and Goslin, 1991). Use of the P[GAL4] line 201Y has made it possible for us to identify MB neurons in heterogeneous primary cultures from Drosophila pupal brain tissue and to study the effect of $20 \mathrm{E}$ on their growth. Furthermore, the majority of pupal Kenyon cells grown for several days in dissociated culture displayed a morphology reminiscent of the natural shape of these cells within the adult MB. This structural fidelity suggests that pupal MB neurons have an endogenous program directing their morphogenetic development, analogous to that proposed for hippocampal pyramidal neurons (Banker and Cowan, 1979; Dotti et al., 1988).

Previous studies of cultured Drosophila neurons of various stages from wild type and mutants allowed morphological and electrophysiological assessment, but without specific identification of the neurons beyond their regional origin (Salvaterra et al., 1987; Byerly and Leung, 1988; Solc and Aldrich, 1988; Wu, 1988; Li and Meinertzhagen, 1995; O’Dowd, 1995; Zhao and Wu, 1997). Primary cultures enriched for MB neurons have been established from brains of other insects (Kreissl and Bicker, 1992; Cayre et al., 1998), but the lack of tools for genetic manipulation limits the versatility of these systems. Acutely dissociated Drosophila MB neurons have been identified using MB-restricted lacZ reporter gene expression in combination with hypotonic loading of a fluorogenic substrate of $\beta$ gal (Wright and Zhong, 1995; Delgado et al., 1998). However, the long-term growth and survival of these Kenyon cells in vitro is poor (Kraft, unpublished observations). Hence, the method described here represents a significant advance, and one with widespread potential application for the study of Drosophila neurons in vitro because of the growing number of P[GAL4] lines for identifying neuronal subsets and UAS lines for expression of reporter genes and effector molecules.

Two particularly intriguing questions regarding the MBs can now be addressed using the cell culture system. The first relates to the molecular heterogeneity detected within the MBs of Drosophila and other insects, which may reflect functionally distinct Kenyon cell populations (Yang et al., 1995; Brotz et al., 1997; Li and Strausfeld, 1997; Tettamanti et al., 1997). In vitro studies can be used to test whether these Kenyon cell subsets differ in their responsiveness to $20 \mathrm{E}$ during pupal development. The second pertains to $\mathrm{MB}$ structural mutations, mushroom bodies deranged $(\mathrm{mbd})$ and mushroom body defect ( $\mathrm{mud}$ ), that markedly disrupt the adult $\mathrm{MB}$ while sparing the larval MB, suggesting aberrant metamorphic reorganization (Technau and Heisenberg, 1982). Growth assessment in dissociated culture should reveal whether mutant Kenyon cells have altered or decreased responsiveness to $20 \mathrm{E}$.

\section{REFERENCES}

Ahmad FJ, Pienkowski TP, Baas PW (1993) Regional differences in microtubule dynamics in the axon. J Neurosci 13:856-866.

Arnold AP, Gorski RA (1984) Gonadal steroid induction of structural sex differences in the central nervous system. Annu Rev Neurosci 7:413-442.

Baas PW (1997) Microtubules and axonal growth. Curr Opin Cell Biol 9:29-36.

Bainbridge SP, Bownes M (1981) Staging the metamorphosis of Drosophila melanogaster. J Embryol Exp Morphol 66:57-80.

Bainbridge SP, Bownes M (1988) Ecdysteroid titers during Drosophila metamorphosis. Insect Biochem 18:185-197.

Balling A, Technau GM, Heisenberg M (1987) Are the structural changes in adult Drosophila mushroom bodies memory traces? Studies on biochemical learning mutants. J Neurogenet 4:65-73.

Banker G, Goslin K, eds (1991) Culturing nerve cells. Cambridge, MA: MIT.

Banker GA, Cowan WM (1979) Further observations on hippocampal neurons in dispersed cell culture. J Comp Neurol 187:469-494.

Barth M, Heisenberg M (1997) Vision affects mushroom bodies and central complex in Drosophila melanogaster. Learn Mem 4:219-229.

Bayer C, von Kalm L, Fristrom JW (1996) Gene regulation in imaginal disc and salivary gland development during Drosophila metamorphosis. In: Metamorphosis: postembryonic reprogramming of gene expression in amphibian and insect cells (Gilbert LI, Tata JR, Atkinson BG, eds), pp 321-361. San Diego: Academic.

Beadle DJ, Lees G, Kater SB, eds (1988) Cell culture approaches to invertebrate neuroscience. New York: Academic.

Brand A (1995) GFP in Drosophila. Trends Genet 11:324-325.

Brand AH, Perrimon N (1993) Targeted gene expression as a means of altering cell fates and generating dominant phenotypes. Development 118:401-415.

Brotz TM, Bochenek B, Aronstein K, ffrench-Constant RH, Borst A (1997) $\gamma$-Aminobutyric acid receptor distribution in the mushroom bodies of a fly (Calliphora erythrocephala): a functional subdivision of Kenyon cells? J Comp Neurol 383:42-48.

Byerly L, Leung H-T (1988) Ionic currents of Drosophila neurons in embryonic cultures. J Neurosci 8:4379-4393.

Caroni P (1997) Intrinsic neuronal determinants that promote axonal sprouting and elongation. Bioessays 19:767-775.

Cayre M, Buckingham SD, Strambi A, Strambi C, Sattelle DB (1998) Adult insect mushroom body neurons in primary culture: cell morphology and characterization of potassium channels. Cell Tissue Res 291:537-547.

Connolly JB, Roberts IJH, Armstrong JD, Kaiser K, Forte M, Tully T, O'Kane CJ (1996) Associative learning disrupted by impaired $\mathrm{G}_{\mathrm{s}}$ signaling in Drosophila mushroom bodies. Science 274:2104-2107.

Consoulas C, Kent KS, Levine RB (1996) Remodeling of the peripheral processes and presynaptic terminals of leg motoneurons during metamorphosis of the hawkmoth, Manduca sexta. J Comp Neurol 372:415-434.

Davis RL, Han K-A (1996) Neuroanatomy: mushrooming mushroom bodies. Curr Biol 6:146-148.

de Belle JS (1995) Drosophila mushroom body subdomains: innate or learned representations of odor preference and sexual orientation? Neuron 15:245-247.

de Belle JS, Heisenberg M (1994) Associative odor learning in Drosophila abolished by chemical ablation of mushroom bodies. Science 263:692-695.

Delgado R, Davis R, Bono MR, Latorre R, Labarca P (1998) Outward currents in Drosophila larval neurons: dunce lacks a maintained outward current component downregulated by cAMP. J Neurosci 18:1399-1407.

Dotti CG, Sullivan CA, Banker GA (1988) The establishment of polarity by hippocampal neurons in culture. J Neurosci 8:1454-1468.

Elgin SCR, Miller DW (1978) Mass rearing of flies and mass production and harvesting of embryos. In: The genetics and biology of Drosophila, Vol 2a (Ashburner M, Wright TRF, eds), pp 112-121. London: Academic. 
Ferveur J-F, Stortkuhl KF, Stocker RF, Greenspan RJ (1995) Genetic feminization of brain structures and changed sexual orientation in male Drosophila. Science 267:902-905.

Fristrom D, Fristrom JW (1993) The metamorphic development of the adult epidermis. In: The development of Drosophila melanogaster (Bate M, Martinez Arias A, eds), pp 843-897. Cold Spring Harbor, NY: Cold Spring Harbor Laboratory.

Futerman AH, Banker GA (1996) The economics of neurite outgrowth - the addition of new membrane to growing axons. Trends Neurosci 19:144-149.

Gallo G, Letourneau PC (1998) Axon guidance: GTPases help axons reach their targets. Curr Biol 8:R80-R82.

Gould E, Woolley CS, Frankfurt M, McEwen BS (1990) Gonadal steroids regulate dendritic spine density in hippocampal pyramidal cells in adulthood. J Neurosci 10:1286-1291.

Hall A (1998) Rho GTPases and the actin cytoskeleton. Science 279:509-514.

Heisenberg M, Borst A, Wagner S, Byers D (1985) Drosophila mushroom body mutants are deficient in olfactory learning. J Neurogenet 2:1-30.

Heisenberg M, Heusipp M, Wanke C (1995) Structural plasticity in the Drosophila brain. J Neurosci 15:1951-1960.

Ito K, Hotta Y (1992) Proliferation pattern of postembryonic neuroblasts in the brain of Drosophila melanogaster. Dev Biol 149:134-148.

Jan LY, Jan YN (1982) Antibodies to horseradish peroxidase as specific neuronal markers in Drosophila and in grasshopper embryos. Proc Natl Acad Sci USA 79:2700-2704.

Kent KS, Levine RB (1988) Neural control of leg movements in a metamorphic insect: persistence of larval leg motor neurons to innervate the adult legs of Manduca sexta. J Comp Neurol 276:30-43.

Kent KS, Levine RB (1993) Dendritic reorganization of an identified neuron during metamorphosis of the moth Manduca sexta: the influence of interactions with the periphery. J Neurobiol 24:1-22.

Kraft R, Levine RB, Restifo LL (1997) Ecdysone enhances the growth of Drosophila pupal mushroom body neurons in cell culture. Soc Neurosci Abstr 23:60.

Kreissl S, Bicker G (1992) Dissociated neurons of the pupal honeybee brain in cell culture. J Neurocytol 21:545-556.

Kurz EM, Sengelaub DR, Arnold AP (1986) Androgens regulate the dendritic length of mammalian motoneurons in adulthood. Science 232:395-398.

Levine RB (1989) Expansion of the central arborization of persistent sensory neurons during insect metamorphosis: the role of the steroid hormone, 20-hydroxyecdysone. J Neurosci 9:1045-1054.

Levine RB, Weeks JC (1996) Cell culture approaches to understanding the actions of steroid hormones on the insect nervous system. Dev Neurosci 18:73-86.

Levine RB, Fahrbach SE, Weeks JC (1991) Steroid hormones and the reorganization of the nervous system during insect metamorphosis. Semin Neurosci 3:437-447.

Levine RB, Morton DB, Restifo LL (1995) Remodeling of the insect nervous system. Curr Opin Neurobiol 5:28-35.

Li C, Meinertzhagen IA (1995) Conditions for the primary culture of eye imaginal discs from Drosophila melanogaster. J Neurobiol 28:363-380.

Li Y, Strausfeld NJ (1997) Morphology and sensory modality of mushroom body extrinsic neurons in the brain of the cockroach, Periplaneta americana. J Comp Neurol 387:631-650.

Liu E, Restifo LL (1998) Identification of a Broad Complex-regulated enhancer in the developing visual system of Drosophila. J Neurobiol 34:253-270.

Luo L, Jan LY, Jan Y-N (1997) Rho family small GTP-binding proteins in growth cone signalling. Curr Opin Neurobiol 7:81-86.

Mackay DJG, Nobes CD, Hall A (1995) The Rho's progress: a potential role during neuritogenesis for the Rho family of GTPases. Trends Neurosci 18:496-501.

Matheson SF, Levine RB (1999) Steroid hormone enhancement of neurite outgrowth in identified insect motor neurons involves specific effects on growth cone form and function. J Neurobiol, in press.

Murphy DD, Segal M (1996) Regulation of dendritic spine density in cultured rat hippocampal neurons by steroid hormones. J Neurosci 16:4059-4068.

O’Dell KMC, Armstrong JD, Yang MY, Kaiser K (1995) Functional dissection of the Drosophila mushroom bodies by selective feminization of genetically defined subcompartments. Neuron 15:55-61.
O'Dowd DK (1995) Voltage-gated currents and firing properties of embryonic Drosophila neurons grown in a chemically defined medium. J Neurobiol 27:113-126.

Power ME (1943) The brain of Drosophila melanogaster. J Morphol 72:517-559.

Prugh J, Croce KD, Levine RB (1992) Effects of the steroid hormone, 20-hydroxyecdysone, on the growth of neurites by identified insect motoneurons in vitro. Dev Biol 154:331-347.

Rees HH, Isaac RE (1985) Biosynthesis and metabolism of ecdysteroids and methods of isolation and identification of the free and conjugated compounds. Methods Enzymol 111:377-410.

Restifo LL, White K (1991) Mutations in a steroid hormone-regulated gene disrupt the metamorphosis of the central nervous system in Drosophila. Dev Biol 148:174-194.

Richards G (1981) The radioimmunoassay of ecdysteroid titers in Drosophila melanogaster. Mol Cell Endocrinol 21:181-197.

Richards G (1997) The ecdysone regulatory cascades in Drosophila. Adv Dev Biol 5:81-135.

Riddiford LM (1993) Hormones and Drosophila development. In: The development of Drosophila melanogaster (Bate M, Martinez Arias A, eds), pp 899-939. Cold Spring Harbor, NY: Cold Spring Harbor Laboratory.

Robinow S, White K (1991) Characterization and spatial distribution of the ELAV protein during Drosophila melanogaster development. J Neurobiol 22:443-461.

Robinow S, Talbot WS, Hogness DS, Truman JW (1993) Programmed cell death in the Drosophila CNS is ecdysone-regulated and coupled with a specific ecdysone receptor isoform. Development 119:1251-1259.

Salvaterra PM, Bournais-Vardiabasis N, Nair T, Hou G, Lieu C (1987) In vitro neuronal differentiation of Drosophila embryo cells. J Neurosci $7: 10-22$.

Sandstrom DJ, Bayer CA, Fristrom JW, Restifo LL (1997) BroadComplex transcription factors regulate thoracic muscle attachment in Drosophila. Dev Biol 181:168-185.

Schubiger M, Wade AA, Carney GE, Truman JW, Bender M (1998) Drosophila EcR-B ecdysone receptor isoforms are required for larval molting and for neuron remodeling during metamorphosis. Development 125:2053-2062.

Schulz RA, Chromey C, Lu M-F, Zhao B, Olson EN (1996) Expression of the D-MEF2 transcription factor in the Drosophila brain suggests a role in neuronal cell differentiation. Oncogene 12:1827-1831.

Smith CL (1994) Cytoskeletal movements and substrate interactions during initiation of neurite outgrowth by sympathetic neurons in vitro. J Neurosci 14:384-398.

Solc CK, Aldrich RW (1988) Voltage-gated potassium channels in larval CNS neurons of Drosophila. J Neurosci 8:2556-2570.

Strausfeld NJ, Buschbeck EK, Gomez RS (1995) The arthropod mushroom body: its functional roles, evolutionary enigmas and mistaken identities. In: The nervous system of invertebrates: an evolutionary and comparative approach (Breidbach O, Kutsch W, eds), pp 349-381. Basel: Birkhäuser.

Streichert LC, Pierce JT, Nelson JA, Weeks JC (1997) Steroid hormones act directly to trigger segment-specific programmed cell death of identified motoneurons in vitro. Dev Biol 183:95-107.

Sun B, Salvaterra PM (1995) Characterization of Nervana, a Drosophila melanogaster neuron-specific glycoprotein antigen recognized by antihorseradish peroxidase antibodies. J Neurochem 65:434-443.

Talbot WS, Swyryd EA, Hogness DS (1993) Drosophila tissues with different metamorphic responses to ecdysone express different ecdysone receptor isoforms. Cell 73:1323-1337.

Tanaka E, Sabry J (1995) Making the connection: cytoskeletal rearrangements during growth cone guidance. Cell 83:171-176.

Technau G, Heisenberg M (1982) Neural reorganization during metamorphosis of the corpora pedunculata in Drosophila melanogaster. Nature 295:405-407.

Technau GM (1984) Fiber number in the mushroom bodies of adult Drosophila melanogaster depends on age, sex and experience. J Neurogenet 1:113-126.

Tettamanti M, Armstrong JD, Endo K, Yang MY, Furukubo-Tokunaga K, Kaiser K, Reichert H (1997) Early development of the Drosophila mushroom bodies, brain centers for associative learning and memory. Dev Genes Evol 207:242-252.

Thummel CS (1996) Flies on steroids-Drosophila metamorphosis and the mechanisms of steroid hormone action. Trends Genet 12:306-310. 
Truman JW (1990) Metamorphosis of the central nervous system of Drosophila. J Neurobiol 21:1072-1084.

Truman JW (1996) Steroid receptors and nervous system metamorphosis in insects. Dev Neurosci 18:87-101.

Truman JW, Reiss SE (1988) Hormonal regulation of the shape of identified motoneurons in the moth Manduca sexta. J Neurosci 8:765-775.

Truman JW, Schwartz LM (1984) Steroid regulation of neuronal death in the moth nervous system. J Neurosci 4:274-280.

Truman JW, Talbot WS, Fahrbach SE, Hogness DS (1994) Ecdysone receptor expression in the CNS correlates with stage-specific responses to ecdysteroids during Drosophila and Manduca development. Development 120:219-234.

Uylings HBM, van Pelt J, Verwer RWH (1989) Topological analysis of individual neurons. In: Computer techniques in neuroanatomy $(\mathrm{Ca}-$ powski JJ, ed), pp 215-239. New York: Plenum.

Vallés AM, White K (1986) Development of serotonin-containing neurons in Drosophila mutants unable to synthesize serotonin. J Neurosci 6:1482-1491.

Vallés AM, White K (1988) Serotonin-containing neurons in Drosophila melanogaster: development and distribution. J Comp Neurol 268:414-428.

VanderHorst VGJM, Holstege G (1997) Estrogen induces axonal outgrowth in the nucleus retroambiguus-lumbosacral motoneuronal pathway in the adult female cat. J Neurosci 17:1122-1136.

Verwer RWH, van Pelt J (1986) Descriptive and comparative analysis of geometrical properties of neuronal tree structures. J Neurosci Methods 18:179-206.

Wang X, Sun B, Yasuyama K, Salvaterra PM (1994) Biochemical analysis of proteins recognized by anti-HRP antibodies in Drosophila mela- nogaster: identification and characterization of neuron specific and male specific glycoproteins. Insect Biochem Mol Biol 24:233-242.

Weeks JC (1987) Time course of hormonal independence for developmental events in neurons and other cell types during insect metamorphosis. Dev Biol 124:163-176.

Weeks JC, Ernst-Utzschneider K (1989) Respecification of larval proleg motoneurons during metamorphosis of the tobacco hornworm, Manduca sexta: segmental dependence and hormone regulation. J Neurobiol 20:569-592.

Woolley CS, McEwen BS (1992) Estradiol mediates fluctuation in hippocampal synapse density during the estrous cycle in the adult rat. J Neurosci 12:2549-2554.

Wright NJD, Zhong Y (1995) Characterization of $\mathrm{K}^{+}$currents and the cAMP-dependent modulation in cultured Drosophila mushroom body neurons identified by lacZ expression. J Neurosci 15:1025-1034.

Wu C-F (1988) Neurogenetic studies of Drosophila central nervous system neurons in culture. In: Cell culture approaches to invertebrate neuroscience (Beadle DJ, Lees G, Kater SB, eds), pp 149-187. New York: Academic.

Wu C-F, Suzuki N, Poo M-M (1983) Dissociated neurons from normal and mutant Drosophila larval central nervous system in cell culture. J Neurosci 3:1888-1899.

Yang MY, Armstrong JD, Vilinsky I, Strausfeld NJ, Kaiser K (1995) Subdivision of the Drosophila mushroom bodies by enhancer-trap expression patterns. Neuron 15:45-54.

Zhao ML, Wu C-F (1997) Alterations in frequency coding and activity dependence of excitability in cultured neurons of Drosophila memory mutants. J Neurosci 17:2187-2199. 